\title{
Cortical Glial Fibrillary Acidic Protein-Positive Cells Generate Neurons after Perinatal Hypoxic Injury
}

\author{
Baoyuan Bi, ${ }^{1 \star}$ Natalina Salmaso, ${ }^{1 \star}$ Mila Komitova, ${ }^{1 \star}$ Maria V. Simonini, ${ }^{1}$ John Silbereis, ${ }^{1}$ Elise Cheng, ${ }^{1}$ Janice Kim, ${ }^{1}$ \\ Suzannah Luft, ${ }^{1}$ Laura R. Ment, ${ }^{2}$ Tamas L. Horvath, ${ }^{3,4,5}$ Michael L. Schwartz, ${ }^{5}$ and Flora M. Vaccarino ${ }^{1,5}$ \\ ${ }^{1}$ Child Study Center and Departments of ${ }^{2}$ Pediatrics, ${ }^{3}$ Comparative Medicine, ${ }^{4}$ Obstetrics/Gynecology and Reproductive Sciences, and ${ }^{5}$ Neurobiology, Yale \\ University School of Medicine, New Haven, Connecticut 06520
}

Glial fibrillary acidic protein-positive $\left(\mathrm{GFAP}^{+}\right)$cells give rise to new neurons in the neurogenic niches; whether they are able to generate neurons in the cortical parenchyma is not known. Here, we use genetic fate mapping to examine the progeny of GFAP ${ }^{+}$cells after postnatal hypoxia, a model for the brain injury observed in premature children. After hypoxia, immature cortical astroglia underwent a shift toward neuronal fate and generated cortical excitatory neurons that appeared synaptically integrated into the circuitry. Fatemapped cortical $\mathrm{GFAP}^{+}$cells derived ex vivo from hypoxic, but not normoxic, mice were able to form pluripotent, long-term selfrenewing neurospheres. Similarly, exposure to low oxygen conditions in vitro induced stem-cell-like potential in immature cortical $\mathrm{GFAP}^{+}$cells. Our data support the conclusion that hypoxia promotes pluripotency in $\mathrm{GFAP}^{+}$cells in the cortical parenchyma. Such plasticity possibly explains the cognitive recovery found in some preterm children.

\section{Introduction}

One percent of live births in the United States are premature and very low birth weight, with a substantial number of these premature infants developing neurological consequences, many of which are attributable to perinatal and postnatal hypoxic-ischemic brain insult (Luu et al., 2009). Nonetheless, a large proportion of affected preterm infants undergo significant cognitive improvement by the time they reach early adulthood (Ment and Constable, 2007). Using a mouse model of perinatal hypoxia (Vaccarino and Ment, 2004; Fagel et al., 2006, 2009; Scafidi et al., 2009), we examined cellular recovery from hypoxic brain injury. This model reproduces the decrease in cortical volume and neuron number in the absence of focal brain infarcts (Weiss et al., 2004; Fagel et al., 2006, 2009), as well as the subtle behavioral disturbances (Chahboune et al., 2009) seen in preterm children (Volpe, 1991, 1998; Kesler et al., 2008). Notably, this model exhibits a restoration in the numbers of cortical neurons several weeks after hypoxic insult, in part attributable to neurogenesis (Fagel et al., 2006, 2009). However, the origin and lineage of the neural stem cells (NSCs) that react to hypoxia are not known,

Received Jan. 30, 2011; revised April 14, 2011; accepted April 24, 2011.

Author contributions: B.B., N.S., M.K., J.S., L.R.M., and F.M.V. designed research;B.B., N.S., M.K., M.V.S., J.S., E.C., J.K., S.L., T.L.H., and M.L.S. performed research; B.B., N.S., M.K., M.V.S., T.L.H., and F.M.V. analyzed data; N.S., M.K., M.V.S., and F.M.V. wrote the paper.

*B.B., N.S., and M.K. contributed equally to this work.

This work was supported by the NIH (P01 NS062686 and R01 NS060750 to F.M.V.). We acknowledge Teresa Sandoval-Minero, Eylem Ocal, Ellen Hoffman, Lauren Provini, Devon Fagel, Allyson Vermaak, Marya Shanabrough, and Erzsebet Borok for technical assistance and useful discussions. We thank William Stallcup at the Burnham Institute for Medical Research (La Jolla, CA) for gifts of NG2 antibodies. We thank Dr. Vittorio Gallo for his comments on this manuscript.

Correspondence should be addressed to Flora Vaccarino, Child Study Center, 230 South Frontage Road, New Haven, CT 06520. E-mail: flora.vaccarino@yale.edu.

DOI:10.1523/JNEUROSCI.0518-11.2011

Copyright $\odot 2011$ the authors $\quad 0270-6474 / 11 / 319205-17 \$ 15.00 / 0$ although this information is crucial for future neural replacement strategies.

NSCs located in the subventricular zone (SVZ) constitutively generate neurons for the olfactory bulb (OB) as well as a small number of oligodendrocytes in adulthood (Luskin, 1993; Lim et al., 2000; Palmer et al., 2000; Menn et al., 2006). NSCs in the SVZ are thought to be a special subset of glial fibrillary acidic protein (GFAP)-expressing astrocytes (Doetsch et al., 1999; Seri et al., 2001; Filippov et al., 2003; Garcia et al., 2004). Although SVZ neurogenesis likely contributes to recovery from postnatal insults (Felling et al., 2006; Yang et al., 2007), it is also possible that progenitors in parenchymal regions of the brain may contribute to this recovery. Indeed, GFAP-positive $\left(\mathrm{GFAP}^{+}\right)$cells with neurogenic potential in vivo have been identified in the early postnatal cerebellum (Zhang and Goldman, 1996; Silbereis et al., 2009, 2010). Astroglial cells with neurogenic potential in vitro have been isolated from the neonatal cortex (Laywell et al., 2000; Berninger, 2010). However, in the adult cortex, this has been achieved only after injury (Buffo et al., 2008).

In vitro hypoxia has been shown to affect the proliferation and differentiation of neural stem and progenitor cells, the extent and direction of this response varying according to the type and region of origin of stem cells (Pistollato et al., 2007; Panchision, 2009; Mohyeldin et al., 2010; Santilli et al., 2010). However, the response of NSCs to chronic hypoxia is poorly understood in vivo. Here, we use a transgenic mouse model to fate map GFAP ${ }^{+}$ cells in vivo and in vitro during the juvenile period to show that these cells give rise to neurons and oligodendrocytes in the cerebral cortex, a process that is enhanced for several weeks after early postnatal hypoxia. In addition, we demonstrate that at least a portion of the newly generated cells arise from $\mathrm{GFAP}^{+}$stem cells located in the cerebral cortex. $\mathrm{GFAP}^{+}$cells can be isolated in great quantities from parenchymal regions of the human brain and maintained in vitro 
(Walton et al., 2006), raising the possibility that these cells can be used for cell replacement in the future.

\section{Materials and Methods}

Transgenic mice, genotyping, and breeding strategy. The GFAPCreER ${ }^{\mathrm{T} 2}$ (GCE) mice (Ganat et al., 2006) were generated as described previously and backcrossed to a C57BL/6 genetic background. GCE transgenic mice carry a Cre recombinase-estrogen receptor type 2 fusion protein $\left(\mathrm{CreER}^{\mathrm{T} 2}\right)$ placed under control of the Gfa2 upstream fragment of the human GFAP ( $h$ GFAP) promoter, which is active in radial glia, astrocytes, and NSCs (Brenner et al., 1994; Ganat et al., 2006). Genotyping was done by PCR using primers to the Cre gene (5'-GCAACGAGTGATGAGGTTCGCAAG-3', forward; 5' TCCGCCGCATAACCAGTGAAACAG-3', reverse) to generate a band of 307 bp (Ganat et al., 2006). GCE mice were crossed with either the R26R LacZ reporter mice (Soriano, 1999) (available from The Jackson Laboratory) or the CAG-CAT-enhanced green fluorescent protein (EGFP) reporter mice (Nakamura et al., 2006) to conduct fate-mapping experiments. Between 3 and 12 animals per group were used in all in vivo fate-mapping experiments; for in vitro neurospheres experiments, the cortex or SVZ of each animal was individually plated and analyzed unless specifically indicated.

The GFAP-GFP transgenic mice [strain name: FVB/N-Tg(GFAPGFP) 14Mes/J; Jackson Laboratory stock \#003257] (donating investigator Dr. Albee Messing, University of Wisconsin-Madison, Madison, WI) were kept on FVB/N genetic background. They were genotyped by PCR using primers to the GFP gene product (475 bp amplicon) (5'-AAGTTGATCTGCACCACC G, forward; 5' -TGCTCAGGTAGTGGTTGTCG, reverse). All animal experiments comply with institutional and national policies and guidelines.

Induction of Cre recombination via intraperitoneal tamoxifen administration. To induce Cre recombination in GFAP promoter-expressing cells, GCE mice crossed with reporter lines were injected with tamoxifen at a dosage of $60 \mathrm{mg} / \mathrm{kg}$ (intraperitoneally) daily from postnatal day 12 (P12) to P14 from a $2 \mathrm{mg} / \mathrm{ml}$ stock solution prepared in autoclaved sunflower seed oil and stored at $-20^{\circ} \mathrm{C}$.

Induction of Cre recombination via intracortical tamoxifen treatment. To induce Cre recombination locally in the cortex, GCE;CAG-EGFP mice at P20 were administered meloxicam as an analgesic and anesthetized under gas isoflurane. Mice were placed in a stereotaxic apparatus, and a cannula packed with tamoxifen crystalline (tamoxifen citrate; Sigma-Aldrich) was aimed at the following coordinates: anteroposterior, $0 \mathrm{~mm}$ (bregma); mediolateral, $1.0 \mathrm{~mm}$; and dorsoventral, between 0.5 and $0.75 \mathrm{~mm}$. When the cannula was in place, we lowered a dummy cannula cut flush to the end of the guide cannula to release the tamoxifen crystal into the cortex; this method of tamoxifen administration has been described previously by several groups to effect hormone-dependent behavior locally in rat hypothalamus (Howard et al., 1984; Wood and Williams, 2001). After this procedure, mice were allowed to recover, were returned to home cages with their mother, and administered a postoperative analgesic (Motrin) for $5 \mathrm{~d}$. Brains were harvested $4 \mathrm{~d}, 3$ weeks, and 6 weeks after tamoxifen administration.

Hypoxic rearing. Mice were placed in a chamber maintaining a 9.5$10.5 \% \mathrm{O}_{2}$ concentration by displacement with $\mathrm{N}_{2}$ as described previously (Turner et al., 2003; Weiss et al., 2004; Fagel et al., 2006). Hypoxia began at $\mathrm{P} 3$ for $8 \mathrm{~d}$ until P11. A separate group of control (normoxic) mice were matched for strain and age. Mice were killed after cessation of hypoxia at P15, P35, or P47. Mice were perfused transcardially with $20 \mathrm{ml}$ of PBS, followed by $35 \mathrm{ml}$ of $4 \%$ paraformaldehyde (PFA). Brains were postfixed overnight in PFA, cryoprotected in a $20 \%$ sucrose solution overnight, and stored at $-80^{\circ} \mathrm{C}$ after embedding in OCT medium.

Isolation and culture of mouse cortical NSCs using the neurosphere assay. Neurosphere cultures were prepared from P15 GCE;CAG-EGFP transgenic mouse brains essentially as described (Rietze and Reynolds, 2006). Briefly, cortical or SVZ tissue dissected out from each mouse was minced using a scalpel blade for $\sim 1 \mathrm{~min}$. The minced tissue was transferred into a trypsin-EDTA solution $(0.25 \% ; 1 \mathrm{ml}$ per two cerebral cortical hemispheres; Invitrogen) using a $1 \mathrm{ml}$ pipette tip. The tube was incubated for $7 \mathrm{~min}$ in a $37^{\circ} \mathrm{C}$ water bath to allow enzymatic breakdown of the tissue sample. At the end of the incubation, an equal volume of 10\% DMEM containing $10 \%$ fetal calf serum (FCS) was added, and the tissue suspension was centrifuged. A suitable volume of PBS with DNase (final concentration, $0.1 \mathrm{mg} / \mathrm{ml}$ ) was added to the pellet to obtain a final volume of $1 \mathrm{ml}$. By using a fire-polished Pasteur pipette, the suspension was triturated until obtaining a single-cell suspension. A Falcon BD Biosciences Discovery Labware cell strainer with $40 \mu \mathrm{m}$ cutoff was used to get rid of cell aggregates and debris, and cells were pelleted by centrifugation at $102 \times g$ for $7 \mathrm{~min}$. The final cell suspension was incubated in stem cell medium composed of DMEM/F-12 (Invitrogen) containing penicillin/ streptomycin, L-glutamine, B27 supplement, N2-supplement (1\%; Invitrogen), epidermal growth factor $(20 \mathrm{ng} / \mathrm{ml})$, and basic fibroblast growth factor $(20 \mathrm{ng} / \mathrm{ml})$ at 500,000 cells per well on uncoated plastic 12-well plates. Neurosphere-like aggregates appeared after 7-10 d. The total number of cell clusters exceeding $80 \mu \mathrm{m}$ in diameter was counted and photographed at $14 \mathrm{~d}$ in vitro using a Carl Zeiss Axio-observed Z1 equipped with phase-contrast microscope and epifluorescence optics and an AxioCam MRm video camera.

To prepare secondary neurospheres, single-cell suspensions made from primary neurosphere clusters were serially diluted in stem cell medium to yield approximately five cells per microliter. A $0.5 \mathrm{ml}$ aliquot was added to each well of a 24 -well plate, and $50 \%$ of the growth medium was exchanged with fresh medium every $48 \mathrm{~h}$.

To analyze the differentiation potential of neurosphere-forming NSCs, single neurospheres were transferred to chamber slides (Nalge Nunc International), and differentiation was induced as described (Nakagomi et al., 2009) in DMEM/F-12 medium without growth factors containing $1 \%$ FCS. Cell clusters in chamber slides were immunostained after $15 \mathrm{~d}$ in culture.

For the in vitro hypoxia neurosphere assay, P8 normoxic mouse cortex from GFAP-GFP transgenic mice [strain name: $\mathrm{FVB} / \mathrm{N}$ $\mathrm{Tg}$ (GFAPGFP) 14Mes/J; Jackson Laboratory stock \#003257] was dissociated, and neurospheres were prepared and cultured as described above, pooling together cortical tissue from four to six pups. Cells were cultured at either 21 or $5 \% \mathrm{O}_{2}$ conditions. For $5 \% \mathrm{O}_{2}$ culturing, cells were incubated in a Series $8000 \mathrm{WJ}$ incubator (Thermo Fisher Scientific) automatic system $\left(5 \% \mathrm{O}_{2}, 5 \% \mathrm{CO}_{2}, 90 \% \mathrm{~N}_{2}\right.$ balance). Secondary and tertiary neurospheres were prepared by dissociating primary neurospheres and plating cells at clonal dilutions as described above. Cell differentiation was induced by culturing secondary and tertiary neurospheres on lamininand poly-ornithine-coated chamber slides as described above in DMEM/ F-12 medium containing $1 \%$ FCS at 5 or $21 \% \mathrm{O}_{2}$.

To prepare low-density monolayer adherent cultures for cellular phenotype characterization of the starting population of cells, secondary neurospheres that were $\mathrm{EGFP}^{+}$were collected and dissociated with gentle mechanical trituration and trypsinization. Dissociated cells were plated at a density of 5000 cells per well in eight-well plastic chamber slides (Nalge Nunc International) and cultured for $24 \mathrm{~h}$ on polyornithine-coated plastic chamber slides in stem cell medium at $21 \% \mathrm{O}_{2}$. Cells were immunostained for EGFP, Sox-2, nestin, GFAP, and brain lipid-binding protein (BLBP), and the fractions among DAPI ${ }^{+}$cells were scored. Between 26 and 177 total cells were evaluated per marker. To analyze the effects of a decreased level of oxygen on cell proliferation and cell death, dissociated cells from GFAP-EGFP ${ }^{+}$neurospheres were cultured for $72 \mathrm{~h}$ in either 21 or $5 \% \mathrm{O}_{2}$ on poly-ornithine-coated plastic chamber slides in stem cell medium. Proliferating cells were identified by Ki67 or 5-bromo-2-deoxyuridine (BrdU) immunostaining after adding BrdU to the medium (final concentration, $10 \mu \mathrm{M}$ ) $2 \mathrm{~h}$ before the cells were fixed. Dying cells were identified by staining for activated caspase- 3 . To identify the types of cells that were undergoing proliferation or cell death, we stained for Sox-2 and GFAP. Between 241 and 389 cells were evaluated per marker.

FACS. GFP ${ }^{+}$Cells were sorted on a fluorescence-activated cell sorter FACSAria or BD FACS Calibur S (BD Biosciences) using FACSDiva software (BD Biosciences). The fluorochromes were excited with the standard $488 \mathrm{~nm}$ laser of this instrument, and GFP was detected using 490 long-pass and 510/20 filters. Cell aggregates and small debris were excluded on the basis of side scatter (measuring cell granularity) and forward scatter (measuring cell size). Background fluorescence was mea- 
Table 1. Antibodies used in this study

\begin{tabular}{|c|c|c|c|}
\hline Antibody & Source & Species & Dilution \\
\hline $\mathrm{APC} / \mathrm{CC} 1$ & Calbiochem & Mouse & $1: 20$ \\
\hline$\beta$-Galactosidase & Cappel & Rabbit & $1: 10,000$ \\
\hline$\beta$-Galactosidase & Abcam & Chicken & $1: 500$ \\
\hline BLBP & Millipore Bioscience Research Reagents & Rabbit & $1: 500$ \\
\hline BrdU/CldU & Accurate Chemical & Rat & $1: 250$ \\
\hline BrdU/IdU & BD Biosciences & Mouse & $1: 100$ \\
\hline Cre & Millipore Corporation & Mouse & $1: 500$ \\
\hline Cre & Novagen & Rabbit & $1: 2000$ \\
\hline Doublecortin & Santa Cruz Biotechnology & Rabbit & $1: 500$ \\
\hline Doublecortin & Santa Cruz Biotechnology & Goat & $1: 500$ \\
\hline GABA & Sigma & Rabbit & $1: 1000$ \\
\hline Gad-67 & Millipore Bioscience Research Reagents & Mouse & $1: 500$ \\
\hline GFAP & Sigma & Mouse & $1: 500$ \\
\hline GFAP & Dako & Rabbit & $1: 1000$ \\
\hline GFP & Invitrogen & Rabbit & $1: 500$ \\
\hline $\mathrm{Hu}$ & Invitrogen & Mouse & $1: 500$ \\
\hline Ki67 & Vector Laboratories & Rabbit & $1: 200$ \\
\hline MAP2 (clone ap20) & Millipore Corporation & Mouse & $1: 250$ \\
\hline Nestin & Millipore Bioscience Research Reagents & Mouse & $1: 2000$ \\
\hline Neuronal nuclei & Millipore Bioscience Research Reagents & Mouse & $1: 500$ \\
\hline $\mathrm{Ng} 2$ & Millipore Corporation & Mouse & $1: 500$ \\
\hline $\mathrm{Ng} 2$ & Dr. William Stallcup & Guinea pig & $1: 500$ \\
\hline $\mathrm{Ng} 2$ & Millipore Bioscience Research Reagents & Rabbit & $1: 500$ \\
\hline 01 & Millipore Corporation & Mouse monoclonal & $1: 50$ \\
\hline $\operatorname{PDGFR} \alpha$ & Dr. William Stallcup & Rabbit & 1:1000 \\
\hline Rip & Developmental Studies Hybridoma Bank & Mouse & $1: 7000$ \\
\hline Sox2 & Millipore Bioscience Research Reagents & Goat & $1: 200$ \\
\hline
\end{tabular}

CldU, 5-Chloro-2-deoxyuridine; IdU, 5-iodo-2-deoxyuridine.

sured using unlabeled cells; these set gating parameters between positive and negative cell populations.

Tissue preparation and immunostaining. Serial $20 \mu \mathrm{m}$ cryosections were obtained as described previously (Ganat et al., 2006). For immunohistochemistry, sections were blocked in PBS containing $0.1 \%$ Tween 20/0.2\% Triton X-100 (PBS-T) containing 10\% goat serum (10\% GS/ PBS-T) or $10 \%$ donkey serum (10\% DS/PBS-T) and then incubated in primary antibody in 5\% GS/PBS-T or DS/PBS-T. For a list of primary antibodies, see Table 1 . Sections were washed thoroughly and then reacted to the secondary antibody of the appropriate species. The secondary antibodies used were as follows: Alexa Fluor 488, Alexa Fluor 594, Alexa Fluor 350, Alexa Fluor 546, and Alexa Fluor 632 (Invitrogen); FITC, rhodamine red X, Cy3, and DyLight 649 (Jackson ImmunoResearch); and aminomethylcoumarin acetate (AMCA 350; Vector Laboratories).

For in vitro immunostaining, neurospheres on coated chamber slides were double or triple immunostained for oligodendrocyte (O1, NG2), astrocyte (GFAP), proliferation (BrdU), and neuronal (MAP2, $\beta$ IIItubulin) markers using a sequential protocol. Live staining was first performed for O1; neurospheres were blocked in DMEM/F-12/5\% GS for $1 \mathrm{~h}$ at $4^{\circ} \mathrm{C}$ and incubated with primary antibody in DMEM/F-12/1\% GS for $3 \mathrm{~h}$ at $4^{\circ} \mathrm{C}$. Samples were washed in DMEM/F-12 and incubated with secondary antibody (1:500, DyLight 649) in DMEM/F-12/1\% GS for $1 \mathrm{~h}$ at room temperature. Neurospheres were then washed in PBS and fixed in $4 \%$ PFA for $20 \mathrm{~min}$ at $4^{\circ} \mathrm{C}$. To stain for BrdU, $2 \mathrm{M} \mathrm{HCl}$ was added to the fixed cells for $30 \mathrm{~min}$ at $37^{\circ} \mathrm{C}$ to denature the DNA. Samples were subsequently blocked in PBS containing 5\% GS and 0.3\% Triton X-100 for 45 min at room temperature and incubated with primary antibodies for other differentiation markers (MAP2, GFAP) in PBS/1\% GS overnight at $4^{\circ} \mathrm{C}$. The next day neurospheres were washed and incubated with secondary antibodies [1:500, Cy3 546 (Jackson ImmunoResearch) and 1:200, AMCA 350 (Vector Laboratories)] in PBS/1\% GS for $45 \mathrm{~min}$ at room temperature.

For flow cytometry analysis, NG2-allophycocyanin (APC) (R \& D Systems)-labeled cells were washed and fixed with 2\% PFA and then reincubated with anti-GFAP-phycoerythrin (PE) (BD Pharmingen). Rat IgG-PE and IgG-APC (BD Pharmingen) served as isotype controls. Data analysis was done using FlowJo software.
Electron microscopy. Animals were perfused, and their brains were processed for immunolabeling for GFP for electron microscopic examination. After identification of a labeled cell in a specific brain region, ultrathin sections were cut on a Leica ultra microtome, collected on Formvar-coated single-slot grids, and analyzed with a Tecnai 12 Biotwin (FEI Company) electron microscope. Nuclear chromatin distribution, cytoplasmic appearance, and organelles as well as synaptic membrane specializations on the perikaryal membranes were followed through consecutive serial sections of the entire labeled cell. Labeled axon terminal, dendrites, and dendritic spines were also analyzed in the neuropil.

Cell counting and microscopic analysis. Unbiased estimates of cell number were obtained via a Carl Zeiss Axioskope 2 Mot Plus attached to a motorized stage and connected to a computer running the Stereoinvestigator Software (MicroBrightField). Serial sagittal sections (one every $600 \mu \mathrm{m}$ ) were used for all counts. Contours of the hippocampus, neocortex (i.e., excluding piriform cortex), and olfactory bulb were drawn. Nuclear profiles of stained cells were counted using the optical fractionator probe with a $40 \times$ oil-immersion objective. Sampling grids sized from $1300 \times 700 \mu \mathrm{m}$ to $300 \times 300 \mu \mathrm{m}$ were adjusted for each staining depending on region under analysis to obtain a relatively constant number of cells sampled. This systematic yet unbiased method provides an estimate of cell density and number that is independent from cell size, shape, orientation, tissue shrinkage, and spatial distribution of the cells (Schmitz and Hof, 2005). Three-dimensional sampling boxes $(250 \times$ $180 \times 10 \mu \mathrm{m}$ or $100 \times 100 \times 10 \mu \mathrm{m})$ with three of six exclusion borders (Gundersen et al., 1988; West, 1993) were automatically placed by StereoInvestigator at each grid intersection point. The density for each cell type was calculated by dividing the total number of cells by the total volume sampled. Cells were assessed and counted for double immunostaining using a dual 594 and $488 \mathrm{~nm}$ exposure filter. Analysis of the subventricular zone, image acquisition, and $Z$-stack analysis were performed on an ApoTome equipped Axiovert 200M with Axiovision 4.5 software (Carl Zeiss).

Statistical analyses. All data was analyzed using Statview 4.51 or SPSS 16.0.2 software. $t$ tests were used with hypoxia (hypoxic or normoxic) as an independent variable. The density of cells per region, total overall number of cells, and, when appropriate, the percentage colocalization with $\beta$-galactosidase $(\beta$-gal) were analyzed. $p$ values were considered significant when $p \leq 0.05$.

\section{Results}

\section{Reporter tagging of astroglial cells after perinatal hypoxic injury}

To track the fate of astroglial cells in the immature brain, we induced $\beta$-gal or EGFP gene expression in cells with GFAP promoter activity. For this purpose, we used the GCE mice, which express a $h G F A P$ promoter-driven $C r e E R^{T 2}$ transgenic construct, able to initiate de novo Cre recombination in astrocytes and NSCs after tamoxifen injection (Ganat et al., 2006). GCE mice carrying the R26R ( $\beta$-gal) or the CAG-CAT-EGFP Cre-inducible reporter genes were reared in a 10\% oxygen environment from P3 to P11 or kept in normal (21\%) oxygen conditions and injected with tamoxifen daily $(60 \mathrm{mg} / \mathrm{kg})$ from P12 to P14.

We first assessed the cell populations initially tagged by reporter gene expression. Consistent with previous data (Ganat et al., 2006), GCE;R26R double-transgenic animals that did not receive tamoxifen demonstrated no recombination, regardless of the survival time after vehicle administration. As expected, $1 \mathrm{~d}$ after the last tamoxifen injection (P15), between 80 and 95\% of the cells expressing the $\beta$-gal or EGFP reporters also expressed the GFAP protein in all brain regions examined (Fig. $1 A-H, P$ ). To assess the phenotype of the reporter ${ }^{+}$cells that were negative for GFAP protein, we determined whether they expressed other glial proteins, including $\mathrm{S} 100 \beta$, Sox 2 , and NG2, or mature markers of neurons and oligodendrocytes. EGFP/GFAP/S100 $\beta$ tripleimmunostaining experiments and stereological counting 
demonstrated that the total number of $\mathrm{EGFP}^{+}$cells in the cerebral cortex was $454,751 \pm 46,900$ in normoxic and $349,615 \pm 112,000$ in hypoxic mice. Of these $\mathrm{EGFP}^{+}$cells, $48.0 \pm 6.8$ and $44.1 \pm$ $2.6 \%$ in normoxic and hypoxic mice, respectively, expressed only GFAP protein; $29.5 \pm 4.8$ and $34.0 \pm 5.9 \%$ in normoxic and hypoxic mice, respectively, expressed both GFAP and $\mathrm{S} 100 \beta$, and the remaining $22.5 \pm 3.2$ and $21.9 \pm 7.4 \%$ in normoxic and hypoxic mice, respectively, expressed S100 $\beta$ alone (Fig. $1 A-H, Q$ ). Thus, in the cerebral cortex, GFAP ${ }^{+}$and $\mathrm{S} 100 \beta^{+}$glia accounted for nearly $100 \%$ of reporter ${ }^{+}$ cells (Fig. 1Q). The targeting efficiency of these cells was fairly low at the dosages of tamoxifen injected: $12.8 \pm 0.02$ and $11.0 \pm 0.04 \%$ of all cortical GFAP/S $100 \beta$ glial cells were reporter ${ }^{+}$in normoxic and hypoxic mice, respectively ( $n=3$ mice per condition). Thus, hypoxic rearing did not change the number of reporter ${ }^{+}$cells in cortex or the percentage of glial cells targeted for fate mapping. We elected to use a low dose of tamoxifen because high doses can be deleterious for nursing pups; although higher doses of tamoxifen can be injected in older mice to achieve higher efficiencies of recombination, this is not required for fate-mapping experiments.

Virtually all the reporter ${ }^{+}$cortical cells expressed Sox2, a transcription factor expressed by embryonic neural stem cells and immature astrocytes (Fig. $1 I-L$ ). In contrast, no reporter ${ }^{+}$cells were colabeled with mature markers for neurons or oligodendrocytes, i.e., NeuN or Rip, at P15 in the cerebral cortex, SVZ or hippocampus in either normoxic or hypoxic conditions, as assessed by both qualitative and stereological sampling (Fig. $1 \mathrm{M}-\mathrm{O}$ and data not shown). However, $12.4 \pm$ $2.0 \%$ of all reporter ${ }^{+}$cells in the cerebral cortex and $13.8 \pm 5.6 \%$ of those in the white matter expressed NG2 and the platelet-derived growth factor receptor $\alpha$ (PDGFR $\alpha$ ) (Fig. 2A,B), markers that are typically coexpressed in oligodendrocyte precursor cells (OPCs) (Nishiyama et al., 1996; Matthias et al., 2003). Similarly, a mouse model expressing inducible Cre under another astroglial promoter, the glial glutamate/aspartate transporter EAAT1/ GLAST, drove reporter expression to a small number of $\mathrm{NG}^{+}$cells (Mori et al., 2006). These data are consistent with the observation (Hachem et al., 2005) that a subset of $S 100 \beta^{+}$cells express NG2 and PDGFR $\alpha$ and thus represent OPCs. Because EGFP would be expressed in both the initially targeted cells and any progeny generated in the time elapsed after the onset of tamoxifen administration, we examined Cre protein expression, which would be specific to those cells initially targeted. We found that, at P15,93\% of Cre ${ }^{+}$cells in the SVZ, $90 \%$ of those in the hippocampus, $100 \%$ of those in the rostral migratory stream (RMS), and $97 \%$ of those in the cortex were $\mathrm{GFAP}^{+}$, and none of the Cre recombinase ${ }^{+}$cells in any region examined were $\mathrm{NG}^{+}$(Fig. 2C,D). To further assess the phenotype of
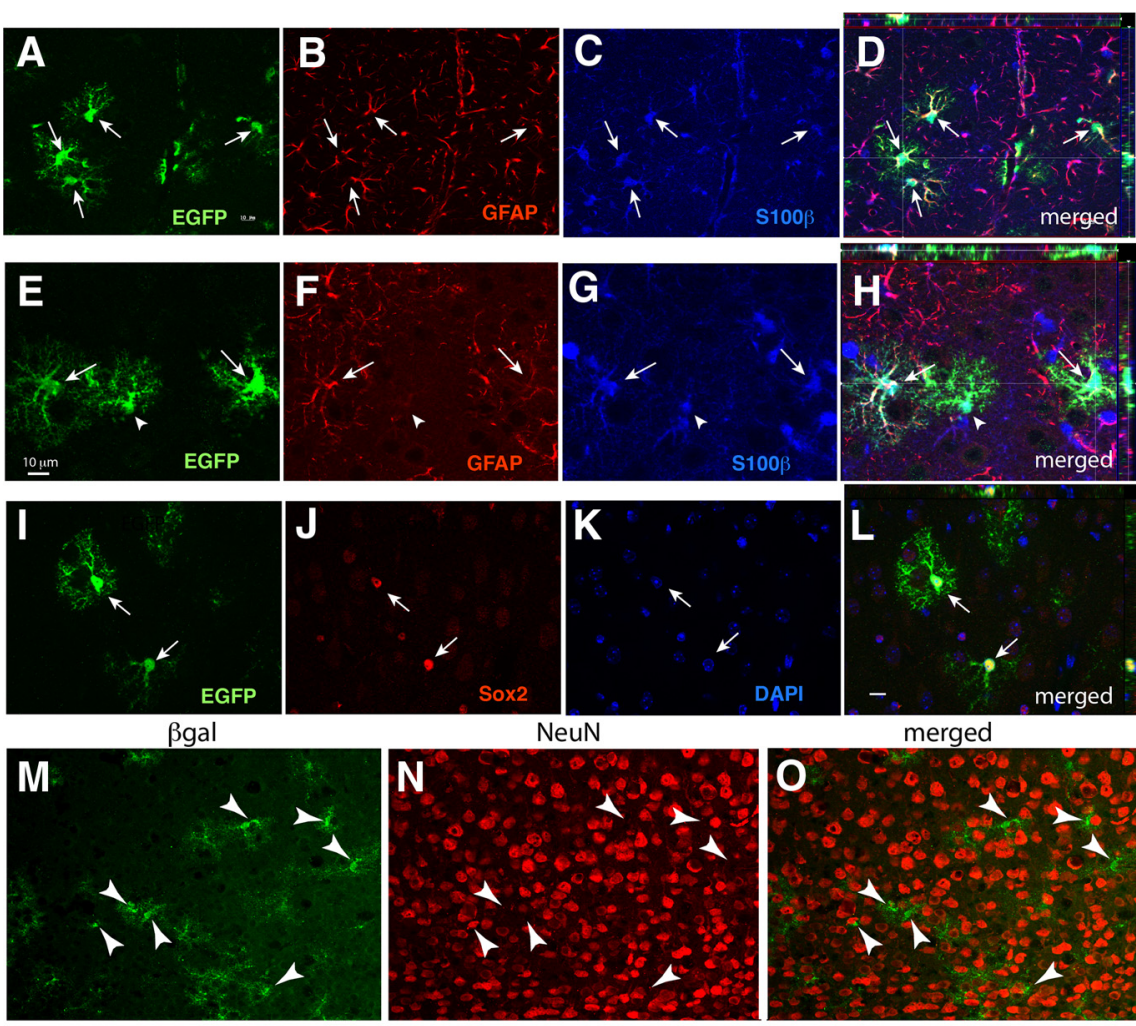

$\%$ reporter+ cells that are GFAP+

Q

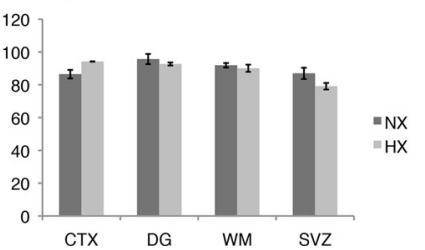

reporter+ cells in the CTX

Reporter expression is initiated in cortical GFAP ${ }^{+}$cells and not in neurons. GCE;R26R and GCE;CAG-EGFP hypoxic corresponding double- and triple-stained cells. Arrowheads in $\boldsymbol{E}-\boldsymbol{H}$ point to a reporter ${ }^{+} / \mathrm{S} 100 \beta^{+}$astroglial cell that has do not coexpress NeuN in the cerebral cortex. $\boldsymbol{P}$ shows that the percentage of reporter ${ }^{+}$cells that are GFAP ${ }^{+}$does not change between hypoxic- and normoxic-reared mice across brain regions. $\mathbf{Q}$ shows that all reporter ${ }^{+}$cells in the cortex expressed GFAP, S100 $\beta$, or both ( $n=4$ mice per condition). Images are $1 \mu \mathrm{m}$ ApoTome single optical sections. CTX, Cortex; DG, dentate gyrus; WM, white matter; NX, normoxic; HX, hypoxic. Scale bar: $\mathbf{A}-\mathbf{O}, \boldsymbol{P}, 10 \mu \mathrm{m} ; \mathbf{Q}, 50 \mu \mathrm{m}$.

the cells initially targeted, we analyzed the mice at P13 after a single tamoxifen injection at P12. This revealed that $100 \%$ of $\mathrm{EGFP}^{+}$cells colocalize S100 $\beta$ immunoreactivity; in one brain, 1 of $26 \mathrm{EGFP}^{+}$ cells expressed weak $\mathrm{NG}_{2}{ }^{+}$immunoreactivity, and no NG2 ${ }^{+}$cells were detected of $16 \mathrm{EGFP}^{+}$cells in another brain. Although the interpretation is complicated by the paucity of $\mathrm{EGFP}^{+}$cells because of the short time between recombination and analysis, this experiment, together with the Cre protein expression, supports the conclusion that Cre recombination and initial reporter gene expression are induced in $\mathrm{GFAP}^{+}$cells and that, subsequently, some astroglial cells differentiate into OPCs between P12 and P15.

\section{Fate of GFAP $^{+}$cells after hypoxia in the cerebral cortex}

We next examined the long-term fate of reporter-targeted $\mathrm{GFAP}^{+}$cells. GCE;R26R and GCE;CAG-EGFP mice reared under hypoxic or normoxic conditions from P3 to P11 and injected with tamoxifen at P12-P14 were killed at P35. Reporter ${ }^{+}$cells 


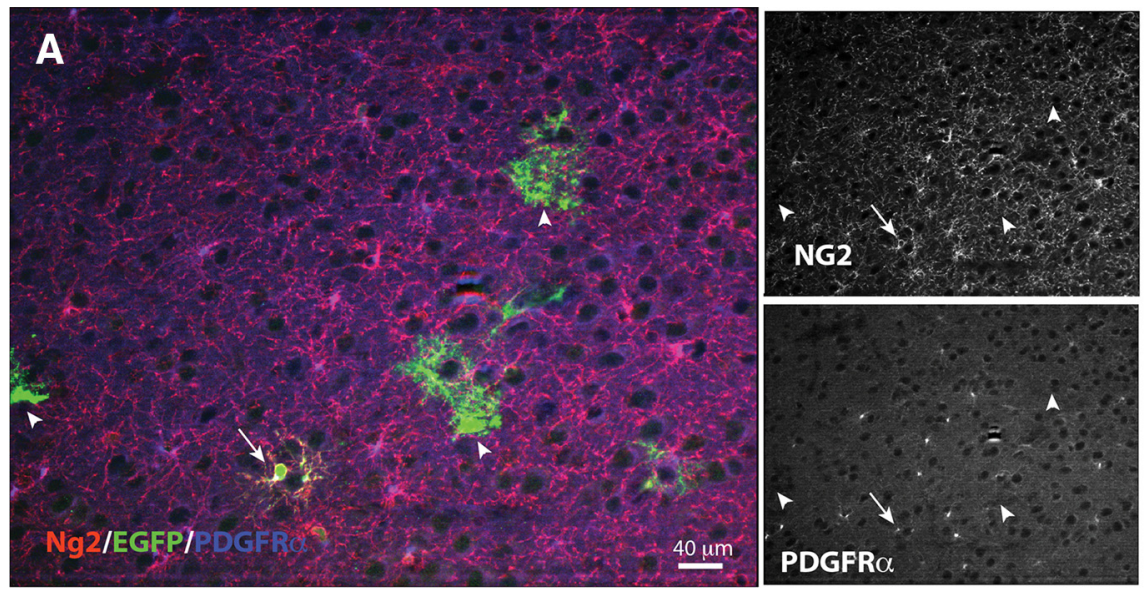

B

\section{$\%$ Reporter+ cells that are PDGFR $\alpha / N G 2+$ at P15}

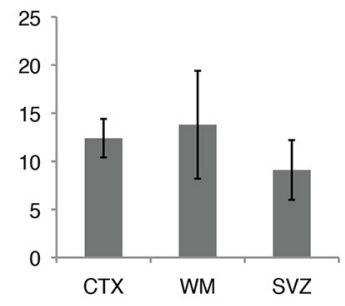

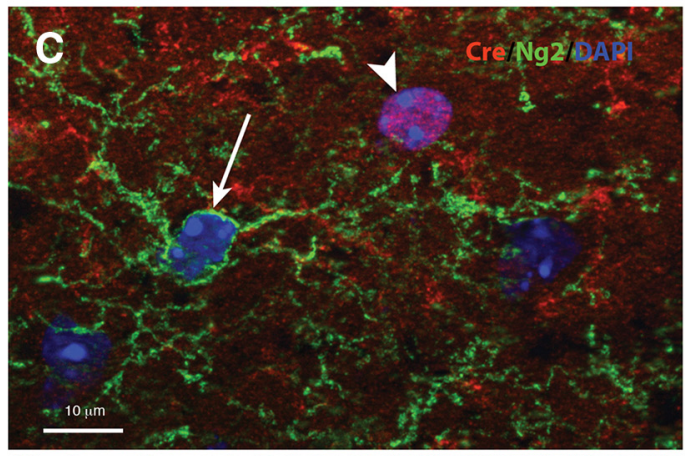

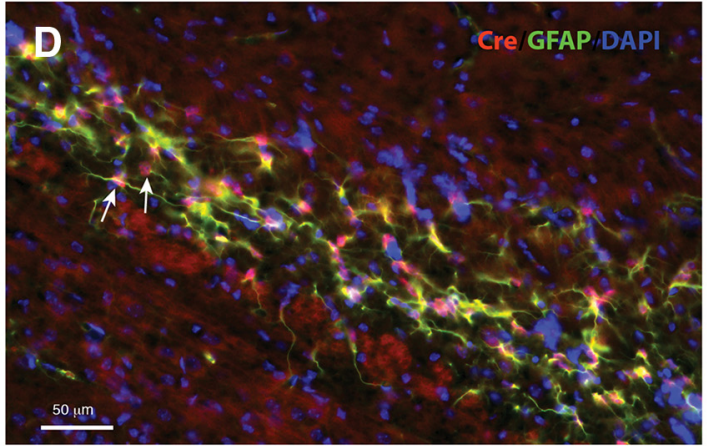

$\%$ Cre that are GFAP+

Lateral SVZ

$92.7 \%$

Hippocampus

$90.2 \%$

RMS

$100 \%$

Ant CTX

$97.1 \%$
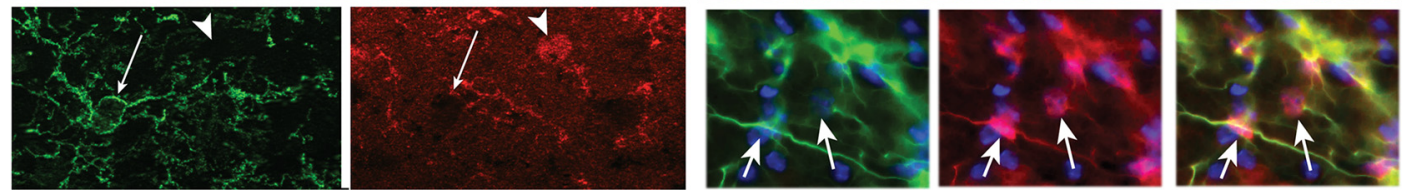

Figure 2. Oligodendrocyte precursors cells arise from fate-mapped GFAP ${ }^{+}$cells at P15. GCE mice carrying the EGFP reporter were analyzed at P15 after tamoxifen injections at P12-P14. A, Triple staining for EGFP, NG2, and PDGFR $\alpha$ in the P15 normoxic cerebral cortex. B, Stereological quantification showing that $\sim 10 \%$ of reporter ${ }^{+}$cells express oligodendrocyte progenitor markers at P15 in normoxic mice; reporter ${ }^{+}$cells express no mature oligodendrocyte markers at this stage. CTX, Cortex; WM, white matter. C, Cre/NG2 double immunostaining (DAPI in blue) in the cortex, demonstrating that Cre expression is not seen in NG2 ${ }^{+}$cells. D. Cre/GFAP double immunostaining (DAPl in blue) in the subcortical white matter and rostral migratory stream (RMS), demonstrating that $\mathrm{Cre}^{+}$cells are $\mathrm{GFAP}^{+}$; percentages of $\mathrm{Cre}^{+}$cells that express GFAP across different brain regions are shown. Ant CTX, Anterior cortex.

were double stained with markers for neurons and glia and analyzed by unbiased stereological methods.

The total number of $\beta$-gal ${ }^{+}$cells did not differ between normoxic- and hypoxic-reared mice at P35. In the cerebral cortex, for example, the number of cortical $\beta$-gal ${ }^{+}$cells were $11,392 \pm 3272$ in normoxia and 13,397 \pm 1837 in hypoxia. However, their fate was different among the two conditions. In the normoxic cerebral cortex (neocortex), $74.4 \pm 4.3 \%$ of the $\beta$-gal ${ }^{+}$ cells were $\mathrm{GFAP}^{+}$astrocytes, $9.0 \pm 1.8 \%$ were $\mathrm{NG}^{+} \mathrm{OPCs}$, $5.75 \pm 0.5 \%$ were Rip ${ }^{+}$oligodendrocytes, and $2.5 \pm 0.9 \%$ of the $\beta$-gal ${ }^{+}$cells expressed the neuronal marker NeuN (Figs. 3, 4E). In the neocortex of mice reared under hypoxia, the proportion of the $\beta$-gal ${ }^{+}$cells expressing GFAP decreased to $61.6 \pm 5.32 \%$, whereas the proportions of cells expressing Rip, NG2, and NeuN increased to $8.29 \pm 2.0,23.9 \pm 6.2$, and $6.4 \pm 0.6 \%$, respectively (Figs. 3, $4 E$ ). Concomitant to the increased proportion of $\beta$-gal ${ }^{+}$ cells exhibiting NeuN expression, the density of $\beta \mathrm{gal}^{+} / \mathrm{NeuN}^{+}$ cells increased from $21.35 \pm 11.1$ cells $/ \mathrm{mm}^{3}$ in normoxia to $77.23 \pm 8.34$ cells $/ \mathrm{mm}^{3}$ of cortex in hypoxia, a 3.5 -fold increase $(p<0.01$, Student's $t$ test) (Fig. $4 J)$. Similarly, the density of Rip ${ }^{+}$ oligodendrocytes in cortex increased from $9.69 \pm 0.62$ to $32.9 \pm$ 7.1 cells $/ \mathrm{mm}^{3}(p<0.05)$ (Fig. 3I-L).

Reporter ${ }^{+}$putative neurons were typically medium to large in size, bipolar, or pyramidal-shaped cells, with a relatively simple dendritic arbor (Fig. 4A-I). NeuN expression was sometimes weaker in the reporter ${ }^{+}$neurons with respect to adjacent ones (Fig. 4G-I). Similar increases in proportion and density in hypoxia-reared mice were noted for reporter ${ }^{+}$cells expressing $\mathrm{Hu}$, an RNA-binding protein expressed by both mature and immature neurons (data not shown). These putative neuronal cells were found as individual cells as well as in doublets or triplets more commonly situated in upper cortical layers and frontal regions.

We examined the reporter ${ }^{+}$putative neuronal cells with immunoelectron microscopy for the presence of morphologically identifiable synaptic connections. At P35, we identified reporter ${ }^{+}$cells with morphological characteristics of neurons, such as loosely arranged chromatin and abundant endoplasmic reticulum; however, these cells did not show morphologically identifiable synaptic boutons on their perikaryal membranes (data not shown). Twelve days later, at P47, morphologically mature $\mathrm{EGFP}^{+}$cortical neurons could be identified, as assessed by the nuclear size, presence of a prominent nucleolus, the conformation of the chromatin, as well as the abundance of the endoplasmic reticulum (Fig. $4 L, M$ ), which were clearly different from the morphology of EGFP ${ }^{+}$mature astrocytes (Fig. $4 K$ ). Astrocytic processes containing electron-dense $\mathrm{EGFP}^{+}$immunolabeled material were seen contacting dendritic spines (Fig. $4 N$ ). We 


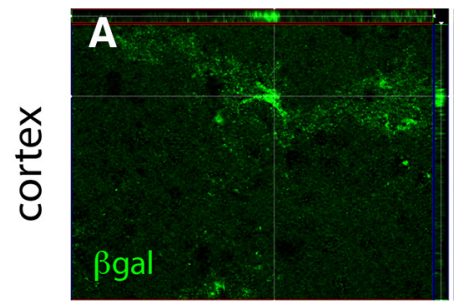

ßgal

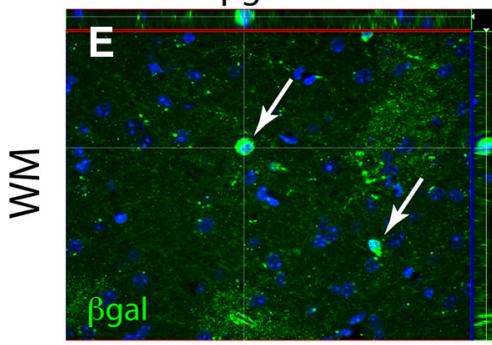

Bgal

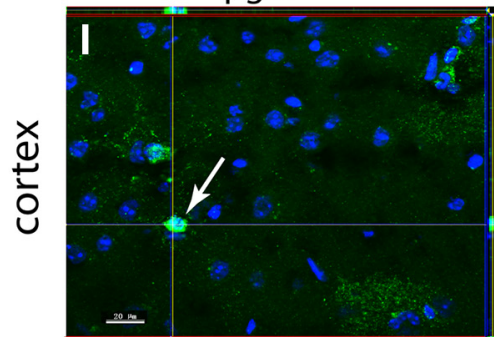

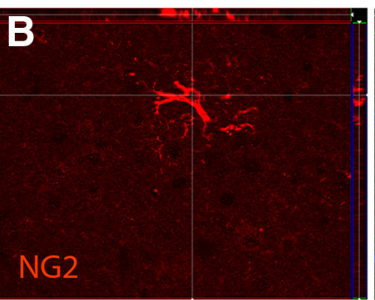

CC1

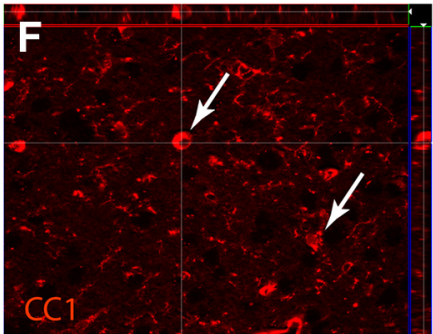

Rip

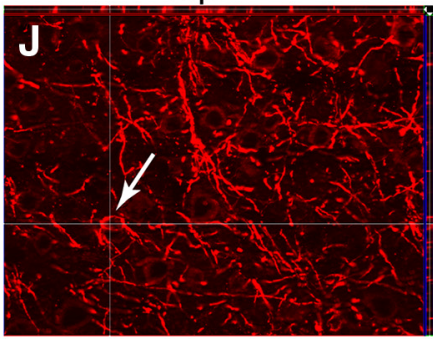

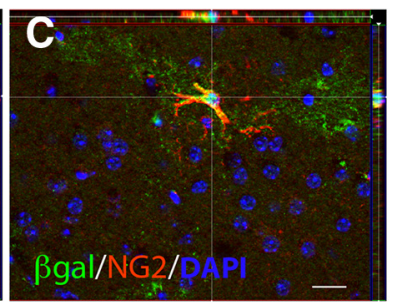

merged

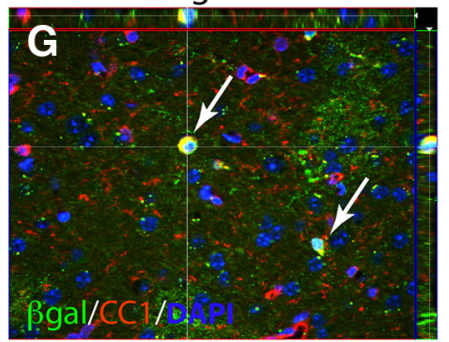

merged

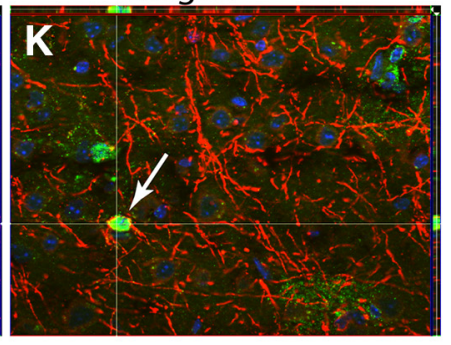

D \% Reporter+ cells expressing oligo markers at P35

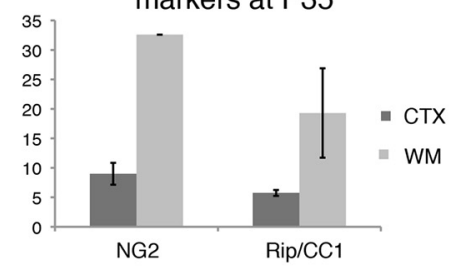

H

Bgal+/CC1+ cells in WM (cells $\left./ \mathrm{mm}^{3} \times 1000\right)$
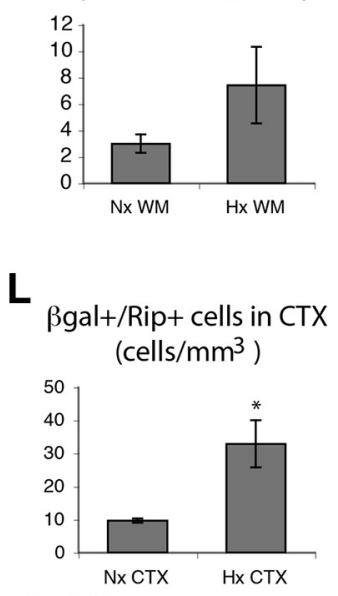

${ }^{*} \mathrm{p}<0.05$

Figure 3. GFAP ${ }^{+}$cells give rise to increased numbers of oligodendrocyte precursors cells and mature oligodendrocytes in hypoxic mice. GCE mice carrying the R26R or the EGFP reporter were analyzed at $\mathrm{P} 35,3$ weeks after tamoxifen injections at P12-P14. $A-C, \beta$-gal/NG2 immunostaining showing a typical NG2 ${ }^{+}$cell expressing the Cre reporter in cortex. Quantification in D shows that, by $\mathrm{P35}$, both NG2 ${ }^{+}$oligodendrocyte progenitors and mature Rip $/ \mathrm{CC} 1^{+}$oligodendrocytes are reporter ${ }^{+}$. $\boldsymbol{E}$ - $\mathbf{G}$, Example of $\beta$-gal/ $/ \mathrm{CC} 1^{+}$cells in the white matter (WM). $\boldsymbol{H}$, Density of $\beta$-gal//CC1 ${ }^{+}$ cells in white matter (WM) of normoxic ( $\mathrm{Nx}$ ) and hypoxic (Hx) animals. $\boldsymbol{I}-\boldsymbol{K}$, Example of $\beta$-gal/Rip ${ }^{+}$cell in cortex. $L$, Density of $\beta$-gal/Rip ${ }^{+}$cells in cortex of normoxic and hypoxic animals. Images are $1 \mu \mathrm{m}$ ApoTome single optical sections. Arrows point to reporter ${ }^{+}$cells that are double positive. Scale bar, $20 \mu \mathrm{m}$.

could also identify $\mathrm{EGFP}^{+}$dendrites and spines establishing synaptic membrane specializations and directly apposed unlabeled boutons with synaptic vesicles (Fig. 4O,P). Furthermore, there were EGFP-labeled synaptic terminals with vesicles contacting unlabeled spines (Fig. 4Q,R).

To assess whether the new cortical neurons arising from fatemapped $\mathrm{GFAP}^{+}$cells were excitatory or inhibitory, we examined the fine morphology and immunocytochemical characteristics of $\mathrm{EGFP}^{+}$cells using antibodies for specific neurotransmitter and transcription factors. We found that, at both P35 and P47, reporter ${ }^{+}$cortical neurons that expressed NeuN were double labeled with T-brain 1 (Tbr1), a transcription factor expressed by early-born glutamatergic cortical neurons (Fig. $4 S-V$ ), and we also found reporter ${ }^{+}$neuronal cells of pyramidal morphology that were Tbr1-negative ( $\mathrm{Tbr} 1^{-}$) and sometimes NeuN negative (Fig. 4W-Z). Fate-mapped astroglial cells did not apparently generate any inhibitory GABAergic neurons in the neocortex, as assessed by immunostaining for the GABA synthetic enzyme glutamate acid decarboxylase (Gad67), the neurotransmitter GABA, or calcium binding proteins typically expressed by GABAergic interneurons. In contrast, reporter ${ }^{+} / \mathrm{NeuN}^{+}$cells in the olfactory bulb were GABAergic (see below).

Effect of perinatal hypoxia on fate of $\mathrm{GFAP}^{+}$cells in the SVZ and white matter

Newly generated cortical neurons observed after the hypoxic insult may originate from the $\mathrm{GFAP}^{+}$NSCs that reside in the SVZ or from within the cortex. In favor of the first possibility, the number of reporter ${ }^{+} /$doublecortin $(\mathrm{Dcx})^{+}$neuronal progenitors in the SVZ were persistently elevated even at P35, a relatively late time point after the hypoxic insult. In the SVZ, $42.6 \% \pm(6.1)$ and $50.3 \%( \pm 2.6)$ of $\beta \mathrm{gal}^{+}$cells expressed Dcx in normoxic and hypoxic animals, respectively $(p<0.05 ; n=3)$. Furthermore, the total number of $\mathrm{Dcx}^{+}$cells and the density of $\beta$-gal ${ }^{+} / \mathrm{Dcx}{ }^{+}$cells in the SVZ were twofold to threefold higher in hypoxic animals at P35, 3 weeks after the insult $(p<0.01)$ (Fig. $5 A-C)$. The classical target for newly generated cells in the SVZ is the olfactory bulb, and, as expected, we observed that hypoxic rearing doubled the density and proportion of reporter ${ }^{+}$GABA inhibitory neurons in this region. The density of $\beta$-gal ${ }^{+} / \mathrm{GABA}^{+}$in the OB at P35 was $277 \pm 114$ and $680 \pm 292$ cells $/ \mathrm{mm}^{3}$ in normoxic and hypoxic mice, respectively $(p<0.05)$. Hypoxic mice displayed an increased number and proportion of reporter ${ }^{+} / \mathrm{Dcx}^{+}$neuronal progenitors as well as reporter ${ }^{+} / \mathrm{NeuN}^{+}$neurons also in the dentate gyrus (data not shown).

In addition to $\mathrm{Dcx}^{+}$progenitor cells, we examined the expression of the transcription factor Tbr2, which plays an important role in the differentiation of cortical excitatory neurons expressing Tbr1 during embryogenesis (Faedo et al., 2002; Englund et al., 2005). As previously observed in adulthood (Brill et al., 2009), we found that Tbr2-immunoreactive cells populate the dorsal extent of the SVZ, RMS, glomerular layer of the OB, and subcortical white matter in juvenile animals; no difference in the total number or density of Tbr $2^{+}$cells was observed between normoxic and 

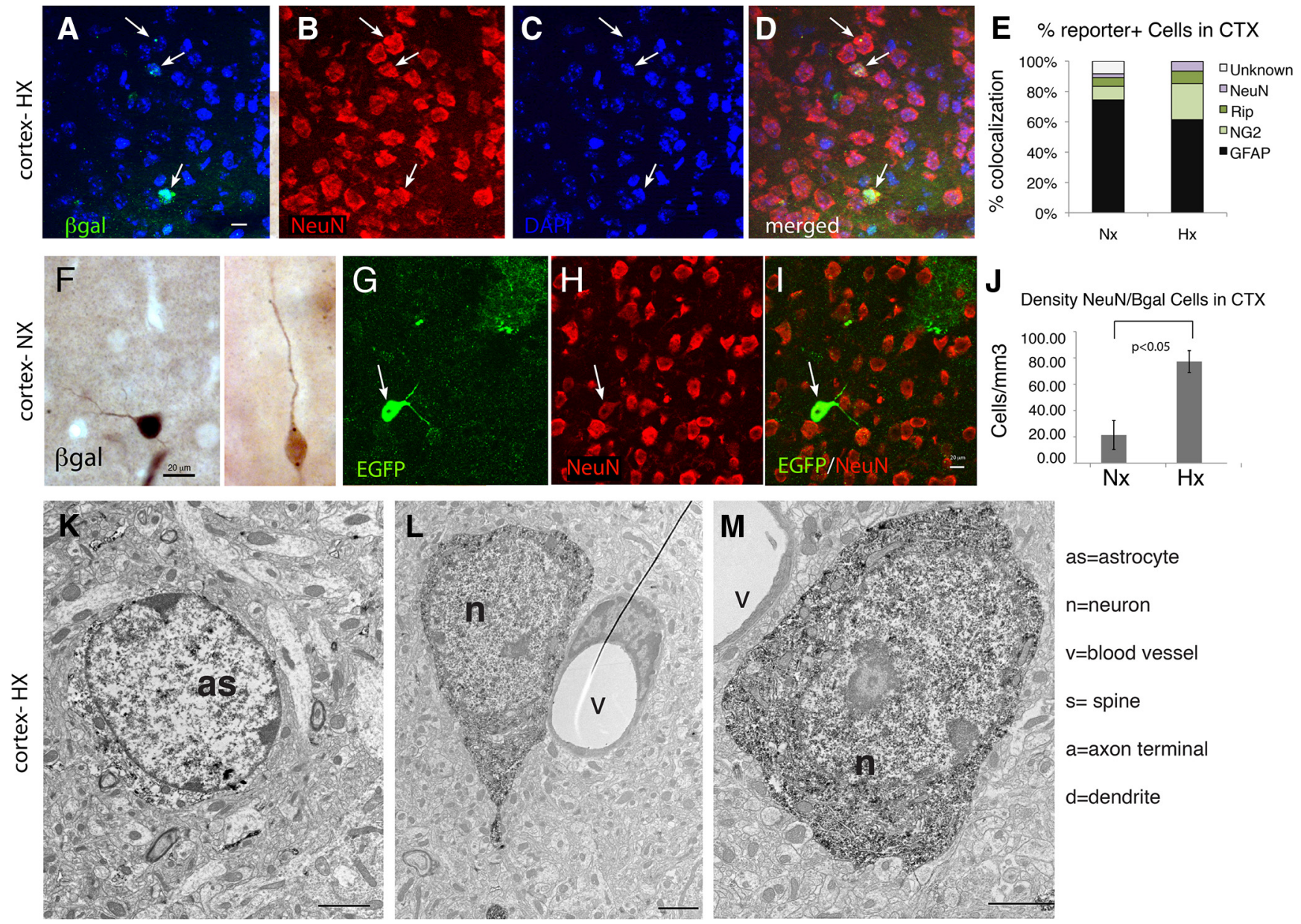

as=astrocyte

$\mathrm{n}=$ neuron

$v=$ blood vessel

$\mathrm{S}=$ spine

$a=a x o n$ terminal

$d=$ dendrite
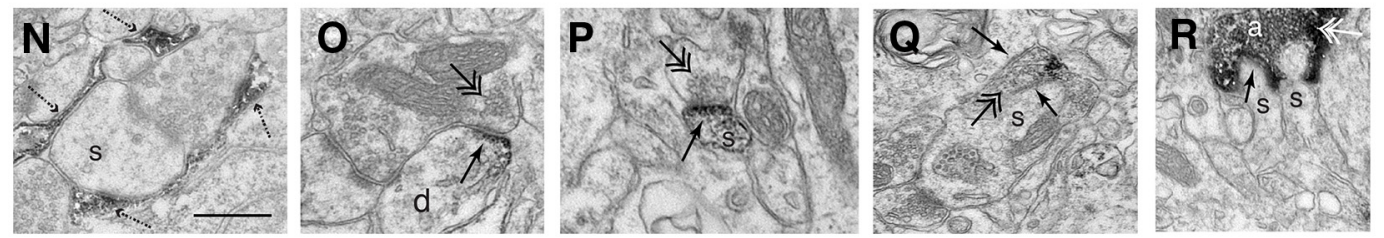

$\ldots \rightarrow \rightarrow$ astrocyte end-feet

$\rightarrow$ synaptic vesicles

$\rightarrow$ post-synaptic site
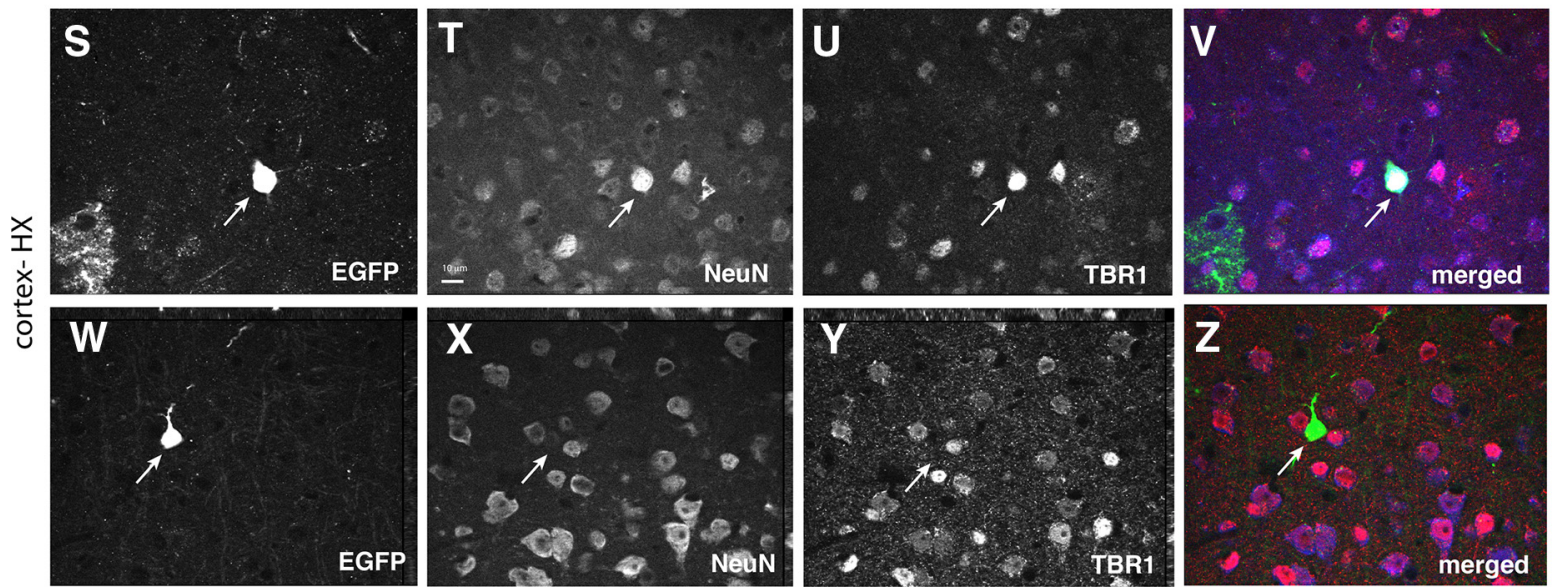

Figure 4. GFAP ${ }^{+}$cells generate cortical neurons. GCE;R26R and GCE;CAG-GFP mice reared under normoxic (Nx) or hypoxic $(\mathrm{Hx})$ conditions as indicated were analyzed at P35 (A-J) or P47 ( $\left.K-Z\right)$ after tamoxifen injections at P12-P14. Sections were double immunostained with $\beta$-gal/NeuN $(\boldsymbol{A}-\boldsymbol{D})$, EGFP/NeuN $(\mathbf{G}-\boldsymbol{I})$, or single stained with $\beta$-gal followed by DAB detection $(\boldsymbol{F})$. Some cortical neurons were NeuN ${ }^{+} /$reporter ${ }^{+}$(arrows) and thus progeny of GFAP ${ }^{+}$cells. The percentage of $\beta$-gal ${ }^{+}$cells that express NeuN, NG2, APC, and GFAP in the cerebral cortex (CTX) is shown in $E$. The density of NeuN $/ \beta$-gal ${ }^{+}$cells is significantly increased in the cortex of hypoxic-reared animals $(\boldsymbol{J})$. Images $\boldsymbol{A}-\boldsymbol{C}$ are $1 \mu \mathrm{m}$ ApoTome single optical sections, and $\boldsymbol{D}$ is a projection of six images spaced $1 \mu \mathrm{m}$ apart. Scale bar, $20 \mu \mathrm{m}$. $\boldsymbol{K}-\boldsymbol{R}$, Newly generated neurons are synaptically connected in the cerebral cortex. GCE;CAG-EGFP mice reared under hypoxia were analyzed by EM after EGFP immunolabeling. Note EGFP immunoprecipitate in astrocyte end feet $(\boldsymbol{N})$, dendrite (arrow in $\mathbf{0}$ ), spines (arrows in $\boldsymbol{P}$ ), and vesicle-containing axon terminals (double arrow in $\mathbf{Q}, \boldsymbol{R}$ ) apposed to synaptic thickening in spines. S-Z, EGFP/NeuN/Tbr1 triple immunostaining, demonstrating instances of reporter ${ }^{+} / \mathrm{NeuN}^{+}$cells that are Tbr $1^{+}(\boldsymbol{S}-\boldsymbol{V})$ and reporter ${ }^{+}$cells of neuronal morphology that are $\mathrm{Tbr}^{-}{ }^{-}$and NeuN ${ }^{-}(\boldsymbol{W}-\boldsymbol{Z})$. Images are $1 \mu \mathrm{m}$ ApoTome single optical sections. 

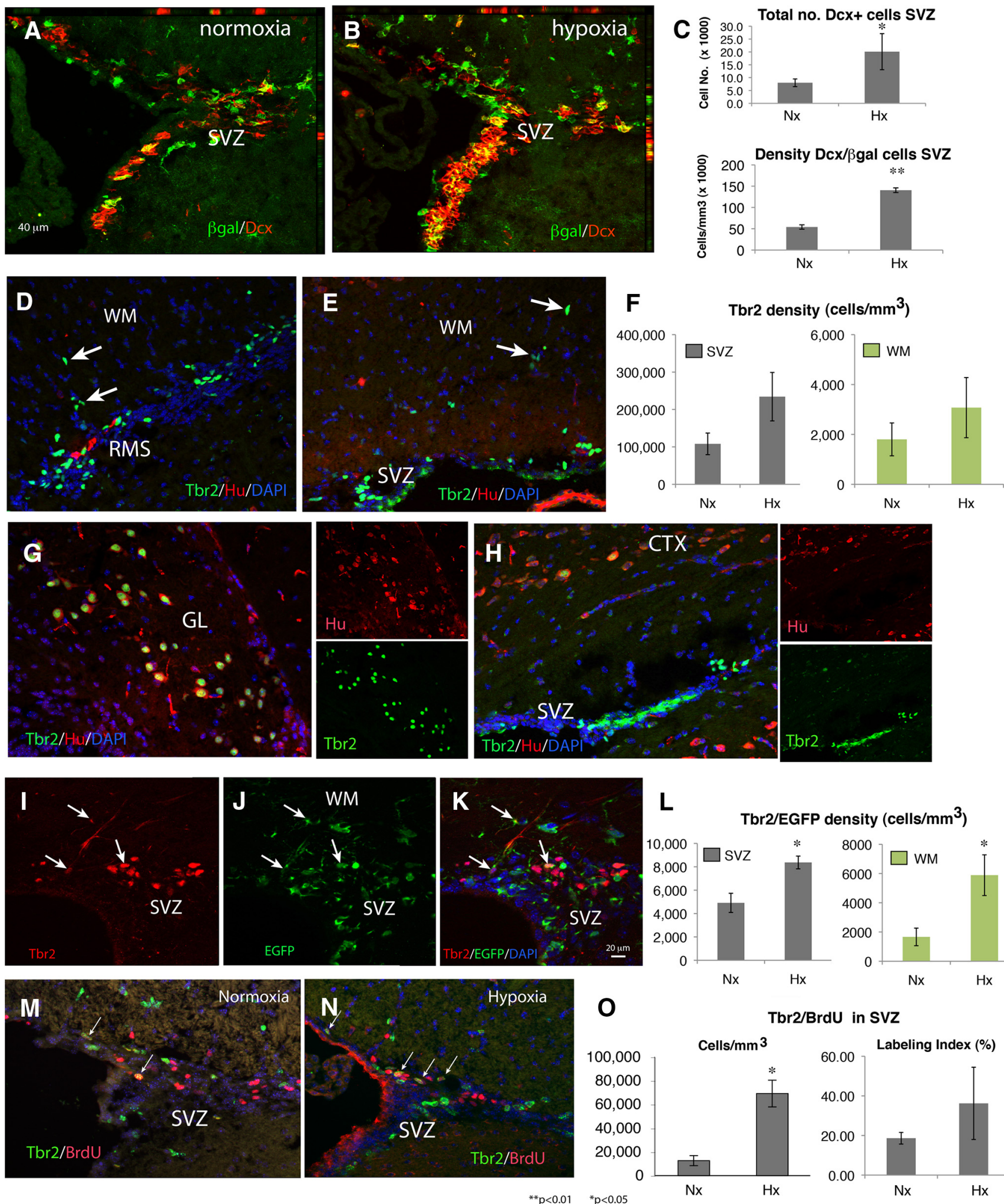

Tbr2/BrdU in SVZ

${ }^{* *} p<0.01 \quad{ }^{*} p<0.05$

Figure 5. Hypoxia-induced amplification of neuronal progenitors derived from GFAP ${ }^{+}$precursors in the SVZ and white matter. GCE;R26R ( $\boldsymbol{A}-\boldsymbol{C}$ ) and GCE;CAG-EGFP ( $\left.\boldsymbol{D}-\mathbf{0}\right)$ mice were tamoxifen injected at P12-P14 and analyzed at P35. $\boldsymbol{A}-\boldsymbol{C}$, In hypoxia-reared animals, the total number of $D c x^{+}$neuronal progenitors and those $D c x^{+}$cells that coexpress $\beta$-gal increased in the SVZ. $\boldsymbol{D}$ - $\boldsymbol{H}$, Tbr2-immunostained cells were observed in the dorsal SVZ and RMS, glomerular layer (GL) of the OB, and boundary of cortex (CTX) with white matter (WM). The Tbr2 ${ }^{+}$cells in the white matter were Hu negative and appeared to undergo chain migration toward the cortex. $I-L, \mathrm{Tbr}^{+} /$/reporter $^{+}$cells (arrows), which arise from fate-mapped GFAP ${ }^{+}$cells, are increased in the SVZ and WM of hypoxic mice. $\mathbf{M - 0}, \mathrm{Tbr2}^{+} / \mathrm{BrdU}{ }^{+}$cells (arrows) increased in the SVZ of hypoxic mice, although the proportion of Tbr2 ${ }^{+}$cells that incorporated BrdU (labeling index) was not significantly changed. Images are $1 \mu \mathrm{m}$ ApoTome single optical sections. Hx, Hypoxic; Nx, normoxic. 

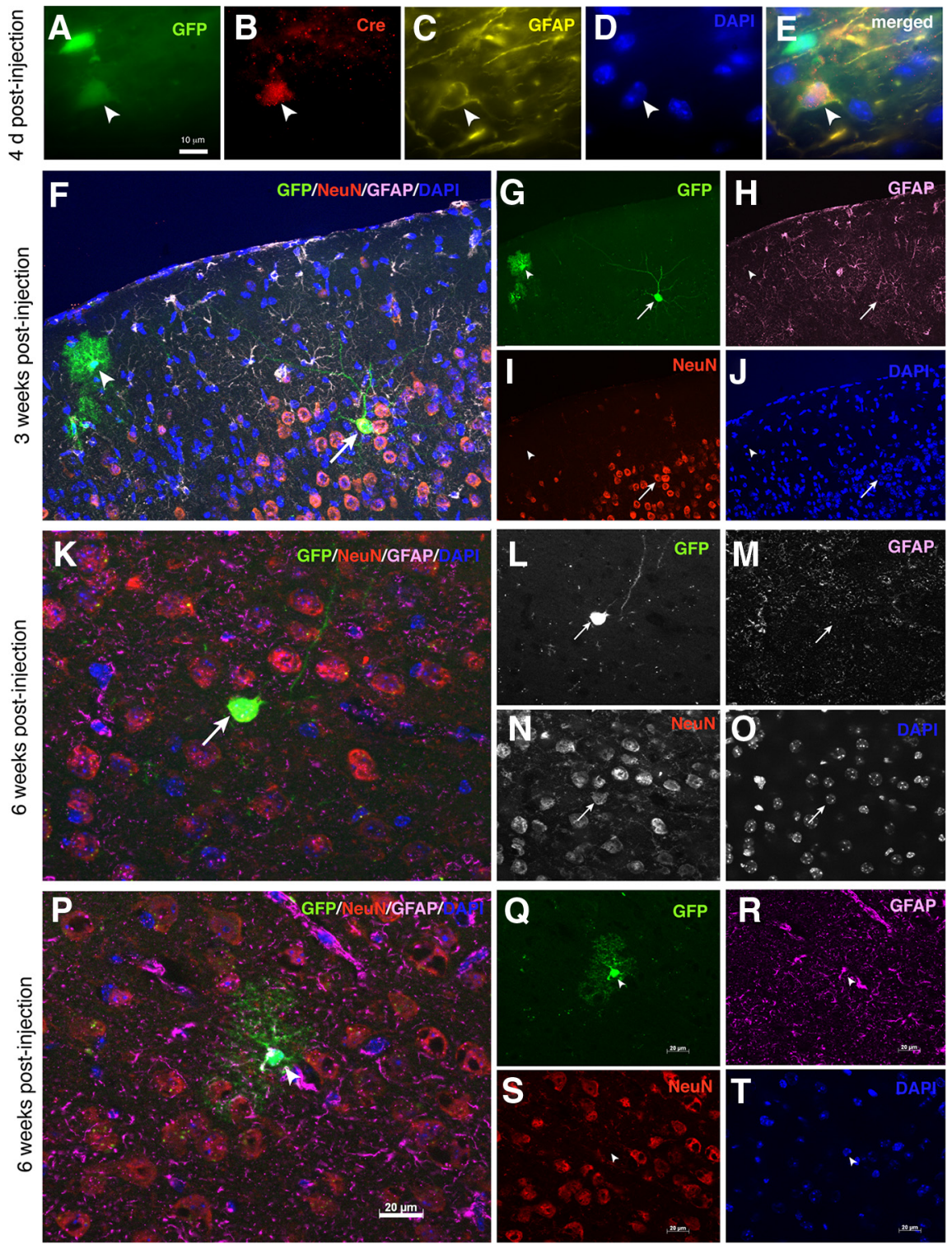

Figure 6. Cortical GFAP ${ }^{+}$cells are able to generate mature astrocytes and neurons. GCE; CAG-GFP mice were reared in hypoxia and then administered intracortical tamoxifen at P20. $\boldsymbol{A}-\boldsymbol{E}$, Four days after tamoxifen injection, Cre protein expression is observed in $\mathrm{GFAP}^{+}$, reporter ${ }^{+}$cells adjacent to the injection tract in the cortex. $\boldsymbol{F}-\boldsymbol{J}$, Three weeks after tamoxifen administration, mature neurons (arrow) and astrocytes (arrowhead) were observed in the cortex of hypoxic animals, several millimeters distal from the point of injection. $\boldsymbol{K}-\boldsymbol{T}$, Mature neurons $(\boldsymbol{K}-\boldsymbol{O})$ and astrocytes $(\boldsymbol{P}-\boldsymbol{T})$ were still observed at 6 weeks after tamoxifen injection of hypoxic animals, suggesting long-term survival of these newly generated cells. Scale bars: (in $\boldsymbol{A}) \boldsymbol{A}-\boldsymbol{E}, 10 \mu \mathrm{m}$; (in $\boldsymbol{P}$ ) $\boldsymbol{F}-\boldsymbol{J}, 40 \mu \mathrm{m}$, $\boldsymbol{K}-\boldsymbol{T}, 20 \mu \mathrm{m} ; \boldsymbol{G}-\boldsymbol{J}, \boldsymbol{L}-\mathbf{O}$, and $\mathbf{Q}-\boldsymbol{T}$ are $50 \%$ reductions of $\boldsymbol{F}, \boldsymbol{K}$, and $\boldsymbol{P}$, respectively.

hypoxic animals in any of these regions (Fig. $5 D-H$ ). In the white matter, clusters and chains of Tbr2 ${ }^{+}$cells exhibited elongated, migratory morphology, extending between the SVZ and RMS up until the boundary with the cortex (Fig. 5D,E). A few, lightly labeled, Tbr $2^{+}$cells were also observed at the inferior border of cortical layer 6 (Fig. $5 H$ ). Tbr2 ${ }^{+}$cells of the SVZ were Hu negative (Fig. $5 D, E$ ) and incorporated BrdU after an acute injection (Fig. 5M-O), suggesting that they are neuronal progenitors. In contrast, $\mathrm{Tbr} 2{ }^{+}$cells in the $\mathrm{OB}$ glomerular layer and cortical layer 6 were uniformly $\mathrm{Hu}^{+}$(Fig. 5G,H) and unable to incorporate BrdU (data not shown), suggesting a differentiated, postmitotic phenotype. In the SVZ and white matter, $14.0 \pm 2.5$ and $20.4 \pm$ $5.1 \%$, respectively, of $\mathrm{Tbr} 2{ }^{+}$cells expressed the EGFP reporter at P35 (Fig. 5I-L). This is similar to the targeting efficiency of $\mathrm{GFAP}^{+}$cells using our protocol and suggests that most or all of

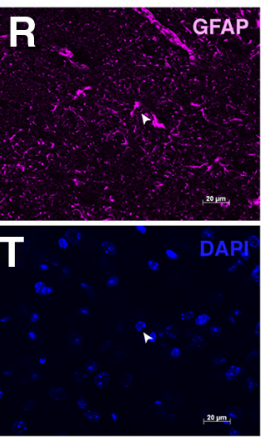

the $\mathrm{Tbr}^{+}$progenitors populating the SVZ and white matter are generated from $\mathrm{GFAP}^{+}$cells in the preceding 3 weeks (P12-P35). In contrast, none of the $\mathrm{Tbr}^{+}$neuronal cells located in the glomerular layer of the OB or cortical layer 6 and only $1.9 \%$ of those in the RMS were reporter $^{+}$(data not shown), suggesting that the $\mathrm{Tbr} 2^{+}$cells observed in these regions were born before tamoxifeninduced targeting or that they originated from a non-GFAP ${ }^{+}$lineage.

Because Tbr2 protein expression in neuronal progenitors of the SVZ is transient, we could not assess whether Tbr $2^{+}$ cells of the SVZ could contribute to generating cortical neurons in hypoxic-reared animals. Nevertheless, we noticed that, in contrast to the density of Tbr $2^{+}$cells, the density of Tbr $2^{+} / \mathrm{EGFP}^{+}$cells in the SVZ and white matter (Fig. $5 L$ ), as well as the density of $\mathrm{Tbr} 2^{+} / \mathrm{BrdU}^{+}$cells in the SVZ (Fig. 5O), were both increased in hypoxic mice compared with the normoxic controls. However, the proportion of Tbr ${ }^{+}$cells that incorporated BrdU (labeling index) was not significantly changed by hypoxic rearing (Fig. 5O), suggesting that hypoxia increases the total number but not the rate of cell division of Tbr2 ${ }^{+}$progenitors at P35.

\section{Origin of GFAP ${ }^{+}$neural stem cells that generate cortical neurons}

Because it has been shown that adult cortical astroglia has neurogenic capacity after stab injury (Buffo et al., 2008; Heinrich et al., 2010), we examined the possibility that $\mathrm{GFAP}^{+} \mathrm{NSC} /$ progenitor cells in the cortex contribute to the increased number of new cortical neurons seen in the present model hypoxic injury. To achieve this, we injected tamoxifen in the cortex of normoxic- and hypoxic-reared GCE; CAG-EGFP mice at P20, 1 week after the cessation of hypoxia, to induce local recombination in $\mathrm{GFAP}^{+}$cells. We first assessed Cre protein expression $4 \mathrm{~d}$ after tamoxifen injections to verify coexpression with GFAP. Indeed, $100 \%$ of cells within the cortex were colabeled by Cre and GFAP antibodies ( $n=5$ animals) (Fig. $6 A-E)$. Furthermore, no ectopic Cre expression was seen in neurons, $\mathrm{NG}^{+}$cells, or oligodendrocytes, suggesting that tamoxifen-induced recombination occurred exclusively in $\mathrm{GFAP}^{+}$cells. To examine the long-term fate of reporter ${ }^{+}$cells, we killed normoxic and hypoxic mice 3 weeks (P41) and 6 weeks (P62) after injection. The range in number of reporter ${ }^{+}$cells that we examined in sections sampled at regular intervals $(1: 5 \mathrm{sec}-$ tions) from the cortex of normoxic $(n=6)$ and hypoxic $(n=6)$ animals at P41 was between 15 and 66, but for most animals, we sampled $\sim 28-35$ reporter ${ }^{+}$cells. Among these, 34 and 51\% were $\mathrm{GFAP}^{+}$in normoxia and hypoxia, respectively; $18 \%$ of reporter cells were $\mathrm{NeuN}^{+}$, but these were observed in hypoxic animals only (Fig. $6 \mathrm{~F}-J$ ). No reporter ${ }^{+} / \mathrm{NeuN}^{+}$cells were seen in nor- 
moxic animals. Because no reporter ${ }^{+} / \mathrm{NeuN}^{+}$cells were observed at the $4 \mathrm{~d}$ time point, these $\mathrm{NeuN}^{+} /$reporter ${ }^{+}$cells should have differentiated from local cortical $\mathrm{GFAP}^{+}$glia over time. We also observed morphologically mature cortical reporter ${ }^{+}$neurons $\left(\mathrm{NeuN}^{+}\right)$and astrocytes $\left(\mathrm{GFAP}^{+}\right)$when we examined animals at 6 weeks after intracortical tamoxifen injection, suggesting long-term persistence of these cells after hypoxic rearing, although the total number of reporter ${ }^{+}$cells were remarkably fewer: in four mice, one animal had no identifiable $\mathrm{EGFP}^{+}$cells in the sampled sections, and the others had a total of 7-11 reporter ${ }^{+}$ cells encompassing one to two $\mathrm{NeuN}^{+}$neurons (Fig. $6 \mathrm{~K}-\mathrm{O}$ ) and six to nine $\mathrm{GFAP}^{+}$astrocytes (Fig. $6 P-T$ ), all in layer $2-3$ of the cortex.

\section{Cortical GFAP ${ }^{+}$reporter-tagged cells generate neurospheres in vitro}

To confirm that the $h$ GFAP promoter-expressing cells in the cortical parenchyma have properties of neural stem/progenitor cells after hypoxic injury, we examined their differentiation potential ex vivo. For these experiments, GCE;CAG-EGFP mice were subjected to the same P3-P11 hypoxia protocol and intraperitoneally injected with tamoxifen at P12-P14 to induce EGFP expression in $h G F A P$ promoter-expressing cells. To assess the identity of the $\mathrm{EGFP}^{+}$cells, cell suspensions prepared from the cerebral cortex of four mice at P15 were immunostained for NG2-APC and GFAP-PE and analyzed by flow cytometry. The results showed that $83 \%$ of the $\mathrm{EGFP}^{+}$cells were $\mathrm{GFAP}^{+}$but not $\mathrm{NG}^{+}$and that $3.5 \%$ of $\mathrm{GFAP}^{+}$cells coexpressed NG2; thus, no $\mathrm{EGFP}^{+}$/ $\mathrm{GFAP}^{-} / \mathrm{NG}^{+}$cells were detected (Fig. $7 A-C$ ). Next, the cerebral cortex and SVZ dissected out from P15 GCE;CAG-EGFP mice were separately dissociated and placed into individual wells under conditions conducive to neurosphere formation for 7-14 d. As expected, neurospheres were formed from the SVZ cell suspension, and these neurospheres were able to form multiple generations of neurospheres after repeated passages (Fig. 7D$F, P, Q)$. There was no difference in the number of primary neurospheres obtained from the SVZ of hypoxic compared with normoxic mice (Fig. $7 D, G, P$ ), but hypoxia induced an increase in neurosphere self-renewal after passage (Fig. $7 E, F, H, I, Q)$.

In contrast to the SVZ, the normoxic cerebral cortex, dissociated and incubated under the same conditions, generated neurosphere-like cell clusters from only 1 animal of 12 after up to $21 \mathrm{~d}$ of incubation in culture; moreover, no secondary neurospheres could be obtained from these preparations (Fig. 7J,P). The data are consistent with the notion that cortical astroglial cells rapidly lose their multipotency during postnatal development (Laywell et al., 2000; Berninger, 2010). In contrast, neurosphere-like cell clusters were observed in cultures derived from the hypoxic cortex already on day 2, and the number of these clusters ( $>80 \mu \mathrm{m}$ in diameter) rapidly increased up to $14 \mathrm{~d}$ after incubation (Fig. $7 \mathrm{~K}$ ). Quantitative analysis $(n=12$ mice) showed that the number of primary neurosphere clusters originating from the cerebral cortex was, on average, $126.9 \pm 50.8$ per well in hypoxic animals, as opposed to $1.66 \pm 0.9$ per well in normoxic animals $(p<0.05)$ (Fig. $7 P$ ).

To determine the clonal potential of neurosphere-forming cortical NSCs, single-cell suspensions from primary neurospherelike clusters derived from the hypoxic cortex were plated after limiting dilution $(<5$ cells/ $\mu \mathrm{l})$ and allowed to grow. On day 14 , formation of secondary neurosphere-like cell clusters was observed (Fig. $7 L, Q$ ). Furthermore, after dissociation and passage by replating cells at clonal density, many generations of neurospheres were obtained in cortical cultures derived from hypoxicreared animals (Fig. 7M). Indeed, we maintained these neurosphere cultures for almost 1 year by repeated passaging. The ability of cells subcultured from hypoxic cortices to selfrenew indefinitely suggests that these cells show neural stem cell properties.

A portion of neurospheres was uniformly green, suggesting that these were derived from a single reporter ${ }^{+}$cell targeted by Cre recombination in vivo (Fig. $7 E, H, L$ ). When single green $\left(\mathrm{EGFP}^{+}\right.$) neurospheres derived from the hypoxic cortex were isolated, dissociated, and replated under the same conditions, they were able to self-renew. At each passage, each green neurosphere generated new, exclusively green neurospheres (Fig. $7 N, O)$. The data suggest that cortical $\mathrm{GFAP}^{+}$cells or their daughters are capable of self-renewal in vitro.

To assess the differentiation potential of the neurosphereforming cells, $\mathrm{EGFP}^{+}$neurospheres that had been passaged several times were plated on chamber slides coated with polyornithine and laminin under differentiating conditions. Immunofluorescence staining and analysis showed that single $\mathrm{EGFP}^{+}$cortical neurospheres generated neurons $\left(\mathrm{MAP}^{+}{ }^{+}\right.$or $\beta$ III-tubulin $\left.{ }^{+}\right)$, astrocytes $\left(\mathrm{GFAP}^{+}\right)$, and oligodendrocyte lineage cells (Olig2 ${ }^{+}$or $\mathrm{NG}^{+}{ }^{+}$) (Fig. $8 A-P$ ). Approximately $75 \%$ of $\mathrm{EGFP}^{+}$neurospheres derived from the hypoxic cortex were able to generate both $\mathrm{MAP}^{+}{ }^{+}$neurons and $\mathrm{GFAP}^{+}$astrocytes (Fig. $8 Q$ ), and similarly, $80 \%$ of the neurospheres were able to generate both $\beta$ III-tubulin ${ }^{+}$neurons and NG2 ${ }^{+}$OPCs (Fig. $8 R$ ). Combined with the results after in vivo tamoxifen injection, these in vitro data strongly suggest that in vivo hypoxia induces or maintains pluripotency and self-renewal potential in a population of $\mathrm{GFAP}^{+}$cells in the parenchyma of the cerebral cortex.

\section{Low oxygen promotes GFAP ${ }^{+} \mathrm{NSCs}$ pluripotency in vitro}

To understand how chronic hypoxia can induce NSC potential and increase neurogenesis from the GFAP lineage, we assessed the effect of decreased oxygen levels in vitro on the proliferation and differentiation of cortical $\mathrm{GFAP}^{+}$cells in the postnatal period. For this purpose, we used GFAP-GFP transgenic mice, in which the EGFP is under direct regulation of the $h G F A P$ promoter. Cerebral cortices were dissected out from four P8 mouse pups and pooled together, and primary neurospheres were obtained under standard conditions $\left(21 \% \mathrm{O}_{2}\right.$ atmosphere $)$ or under $5 \% \mathrm{O}_{2}$ and passaged at clonal cell density $(<5$ cells $/ \mu \mathrm{l})$ to generate secondary neurospheres under their respective culture conditions ( 21 or $5 \% \mathrm{O}_{2}$ for $10-14 \mathrm{~d}$ ) (Fig. $9 \mathrm{~A}$ ).

To further characterize the effect of differential oxygen exposure on the neurosphere-forming cell population, randomly isolated GFAP-EGFP ${ }^{+}$secondary neurospheres cultured in $21 \% \mathrm{O}_{2}$ were dissociated and cultured at clonal dilutions for $3 \mathrm{~d}$ on polyornithine-coated plastic chamber slides in stem cell medium. The phenotype of the cell population was first characterized at $24 \mathrm{~h}$ after cell dissociation by immunostaining for cellular markers. The results showed that $100 \%$ of DAPI ${ }^{+}$cells were Sox $2^{+}, 80 \%$ were $\mathrm{EGFP}^{+}, 75 \%$ expressed GFAP protein, $49 \%$ were nestin ${ }^{+}$, and $62 \%$ were $\mathrm{BLBP}^{+}$, suggesting that the majority of these cells were neural stem/progenitor cells with radial glial cell characteristics (Fig. 9B). An independent cell preparation from three individual GFAP-GFP mouse cortices showed similar percentages of GFAP and EGFP expression. Dissociated cells were then cultured for $3 \mathrm{~d}$ in differential oxygen levels to study cell proliferation and cell death. At this time, 99.2 and $99.7 \%$ of the cells were Sox $2^{+}$in 21 and $5 \% \mathrm{O}_{2}$, respectively, and 56 and $63 \%$ were $\mathrm{GFAP}^{+}$in 21 and $5 \% \mathrm{O}_{2}$, respectively $\left(n=389\right.$ and $398 \mathrm{DAPI}^{+}$cells scored in the two conditions), revealing no drastic change in phenotype after a few days of low oxygen exposure. Furthermore, $3 \mathrm{~d}$ expo- 


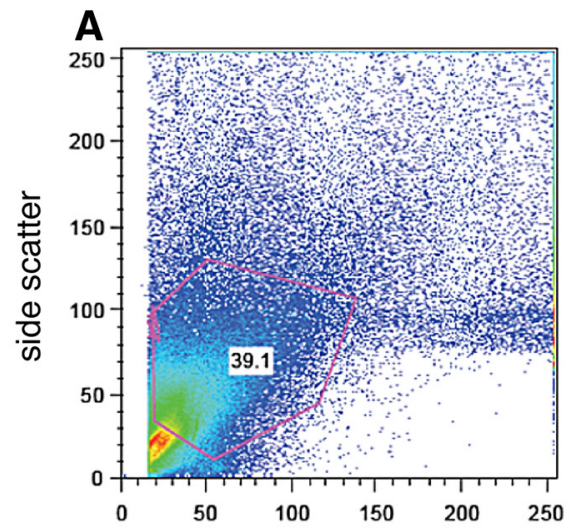

Forward scatter

1st NS culture SVZ
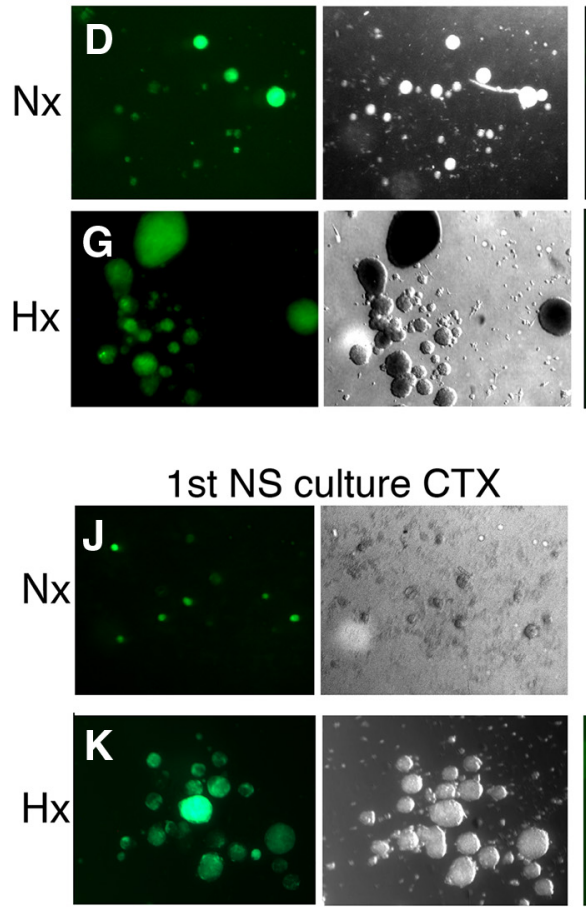

\section{NS culture CTX}

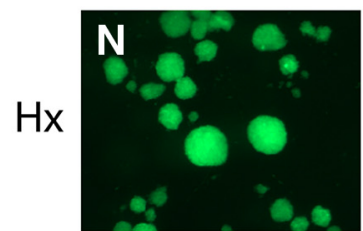

EGFP

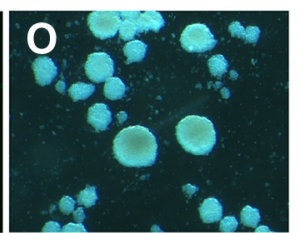

phase contrast

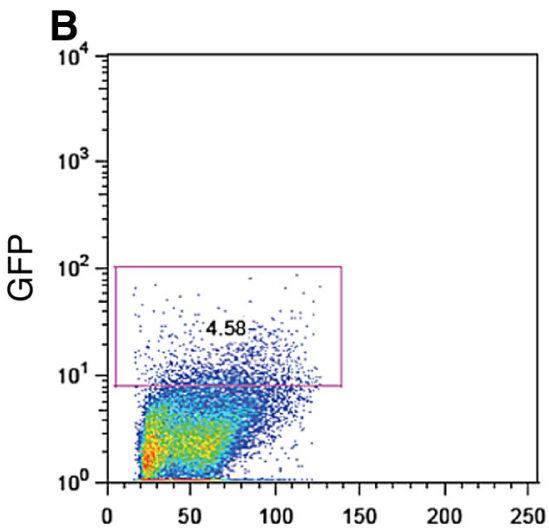

Forward scatter

\section{2nd NS culture SVZ}
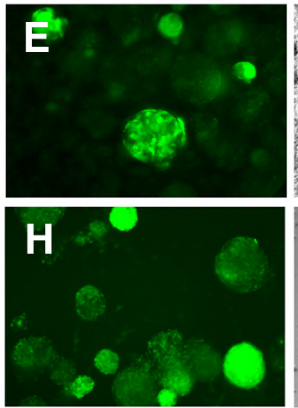

2nd NS culture CTX

none
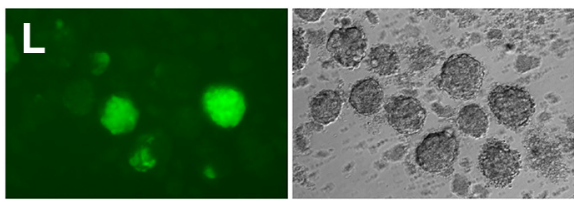

P Primary Neurospheres

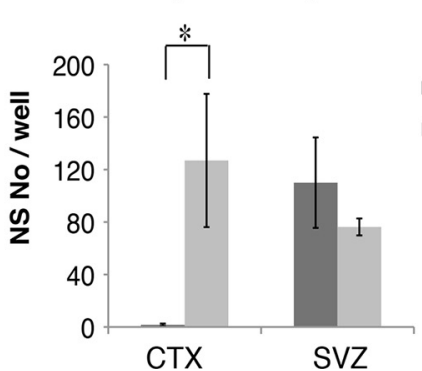

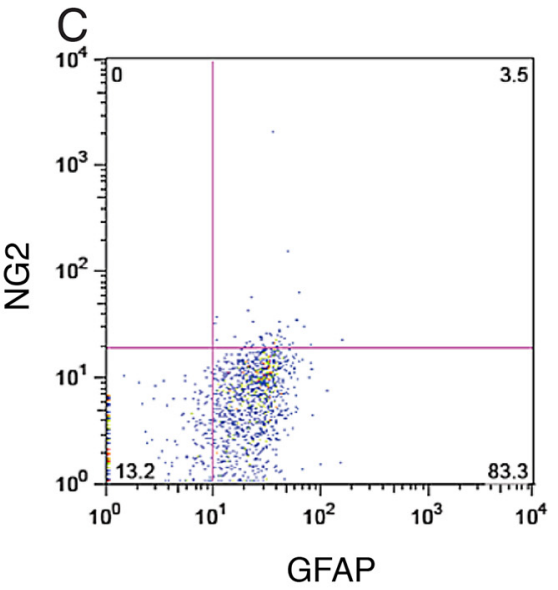

Long-term NS culture SVZ
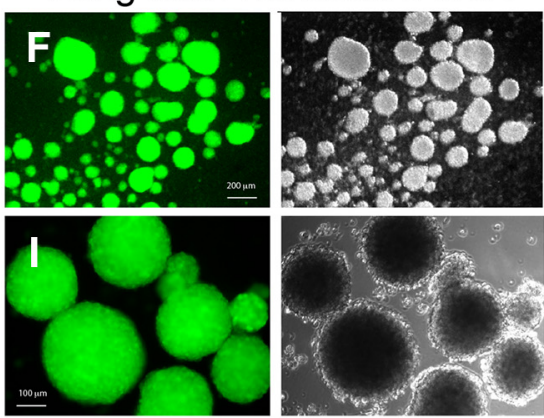

Long-term NS culture CTX none
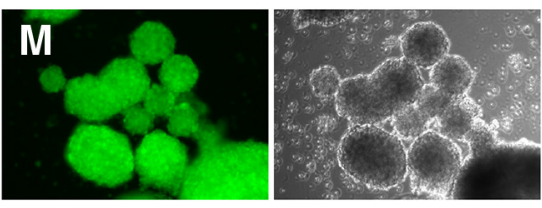

Q Secondary Neurospheres
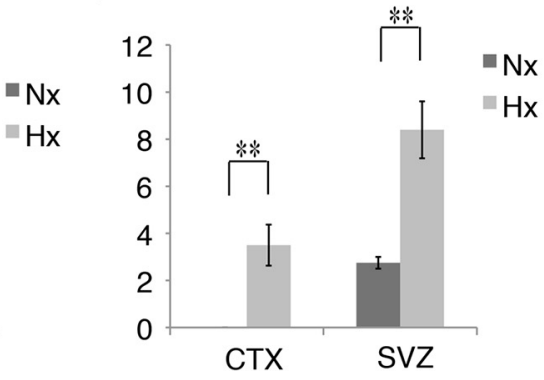

Figure 7. Cortical GFAP ${ }^{+}$cells tagged in vivo with EGFP in GCE mice can generate neurospheres in hypoxic but not normoxic mice. A-C, Analysis of NG2 ${ }^{+} / \mathrm{GFAP}^{+} / \mathrm{GFP}^{+}$cells by flow cytometry. Dot plots of dissociated cells from GCE;CAG-EGFP transgenic mouse cortices in forward and side scatter with a polygon indicating the gate selecting the viable cells $(\boldsymbol{A})$; GFP ${ }^{+}$cells were gated based on the negative control cells $(\boldsymbol{B})$. GFP ${ }^{+}$cells were further analyzed according to fluorescence intensity for GFAP-PE ( $x$-axis) and NG2-APC ( $y$-axis) (C). D-I, Neurosphere (NS)-like cell clusters were obtained from the SVZ of both normoxic ( $\mathrm{Nx}$ )- and hypoxic ( $\mathrm{Hx}$ )-reared mice at P15. J-M, Neurosphere-like cell clusters were obtained from the hypoxic, but not the normoxic, cerebral cortex (CTX) at P15. $\mathbf{N}, \mathbf{O}$, Single green primary neurospheres from the hypoxic cortex dissociated and plated at clonal dilution generated exclusively green neurospheres, suggesting that a GFAP ${ }^{+}$cell or its progeny were able to self-renew. $\boldsymbol{P}, \mathbf{Q}$, The total number of cell clusters ( $>80 \mu \mathrm{m}$ in diameter) harvested from the different region was quantified $10-14 \mathrm{~d}$ after incubation ( $n=12$ per condition). For the SVZ, in vivo hypoxia increased the number of secondary neurospheres; for the cortex, hypoxia was required for both primary and secondary neurosphere formation. ${ }^{*} p<0.05$; ${ }^{* *} p<0.001$. 

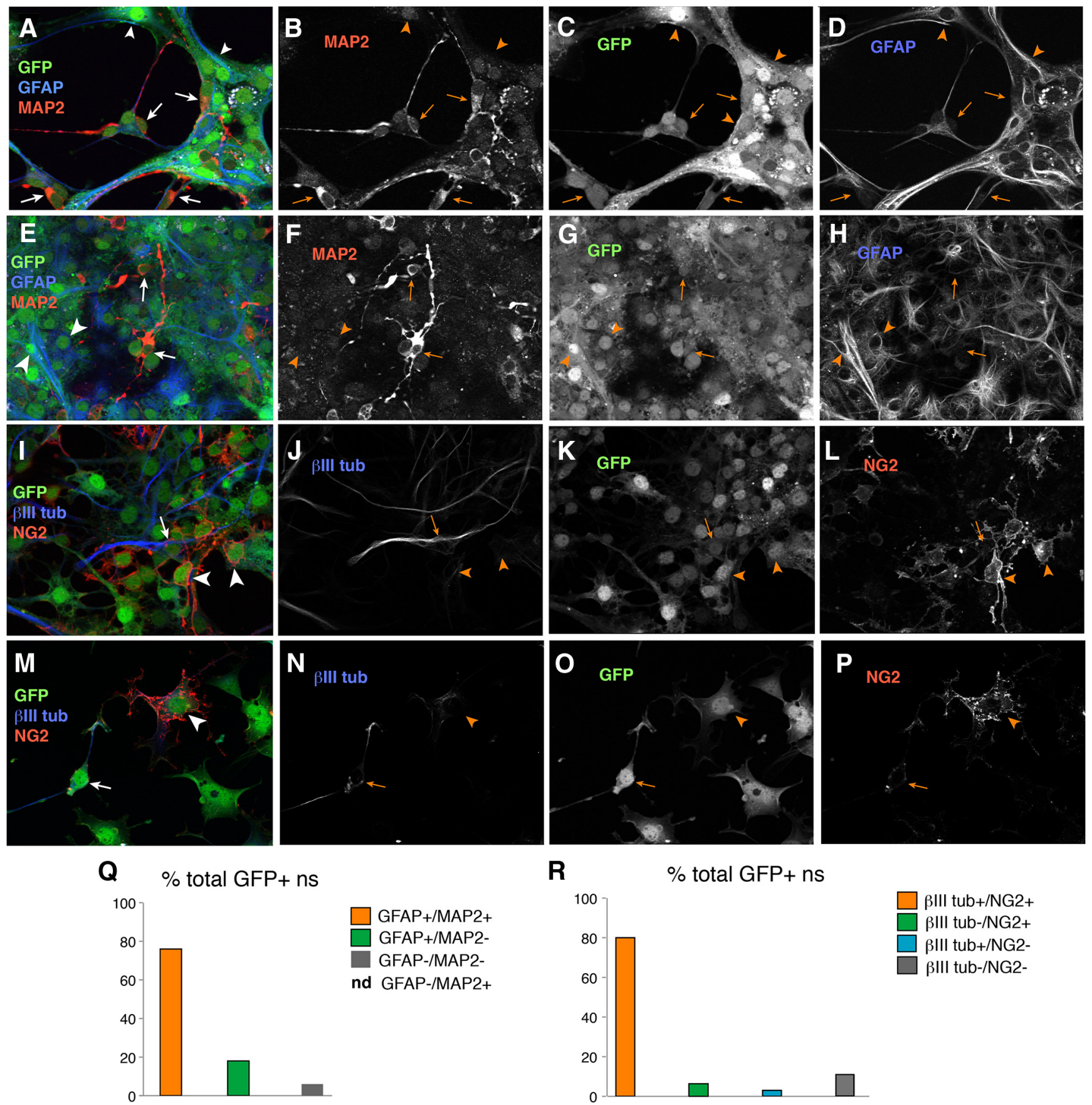

$\mathbf{R}$

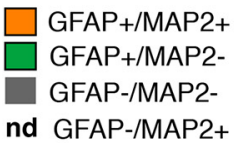

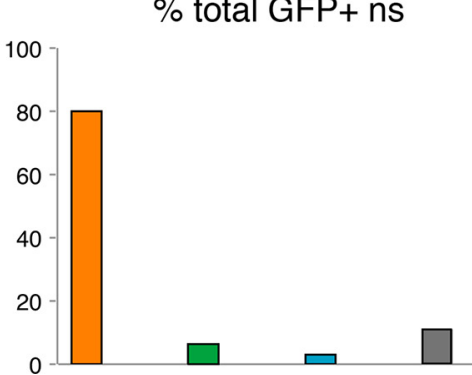

$\square \beta I I I$ tub+/NG2+ $\beta$ III tub-/NG2+ BIII tub+/NG2ßIII tub-/NG2-

Figure 8. Immunocytochemical analysis of differentiated EGFP ${ }^{+}$neurospheres generated from hypoxic cortex. $\boldsymbol{A}-\boldsymbol{D}$ and $\boldsymbol{E}-\boldsymbol{H}, \mathbf{M a g n i f i e d}$ views of single neurospheres cultured for $10 \mathrm{~d}$ under differentiation conditions exhibiting MAP2 neurons (arrows) and GFAP ${ }^{+}$astrocytes (arrowheads). $\boldsymbol{I}-\boldsymbol{L}$ and $\boldsymbol{M}-\boldsymbol{P}$, Magnified views of single neurospheres exhibiting $\beta$ III-tubulin ${ }^{+}$neuronal (arrows) and NG2 ${ }^{+}$OPCs (arrowheads). Q, Quantification of the percentages of EGFP ${ }^{+}$neurospheres (ns) containing MAP2 ${ }^{+}$neurons, GFAP ${ }^{+}$astrocytes, or both ( $n=40$ neurospheres analyzed). nd, Not determined. $\boldsymbol{R}$, Quantification of the percentages of EGFP ${ }^{+}$neurospheres containing $\beta$ III-tubulin ${ }^{+}$neurons and NG2 ${ }^{+}$oligodendrocyte progenitors or both $(n=40$ neurospheres analyzed). All neurospheres are from hypoxic cortex.

sure to either standard $\mathrm{O}_{2}$ or $5 \% \mathrm{O}_{2}$ did not affect the number of proliferating cells identified by Ki67 immunostaining. For cultures kept in $21 \% \mathrm{O}_{2}, 63 \%$ were $\mathrm{Ki}^{+}{ }^{+}$(233 of 369 cells), and for cultures kept in $5 \% \mathrm{O}_{2}, 63 \%$ were also $\mathrm{Ki}^{+} 7^{+}(228$ of 360 cells). Similarly, lower $\mathrm{O}_{2}$ did not seem to affect the percentage of cells in $\mathrm{S}$ phase, as assessed by a short-term BrdU incorporation. For cultures kept in $21 \% \mathrm{O}_{2}, 3.8 \%$ were $\mathrm{BrdU}^{+}$( 13 of 346 cells), and for cultures kept in $5 \% \mathrm{O}_{2}, 4.4 \%$ were $\mathrm{BrdU}^{+}$(17 of 389 cells). Among GFAP $^{+}$cells in dissociated cultures kept in $5 \% \mathrm{O}_{2}, 18 \%$ expressed Ki67, whereas among Sox- ${ }^{+}$cells,
92\% coexpressed Ki67. A similar pattern was observed in cultures kept in $21 \% \mathrm{O}_{2}$. This suggests that cultures of cortexderived astroglial stem cells exhibited a profile similar to SVZ astroglial NSC, with slowly proliferating $\mathrm{GFAP}^{+}$stem cells and fast amplifying progenitors.

At $24 \mathrm{~h}$ after plating, oligodendrocyte lineage cells and, after $10 \mathrm{~d}$ in cell culture, neurons and oligodendrocyte-like cells could be found adjacent to $\mathrm{EGFP}^{+}$and $\mathrm{GFAP}^{+}$cells (Fig. 9B), suggesting that these neural stem/progenitor cells had given rise to more differentiated progeny. The differentiated progeny of $\mathrm{GFAP}^{+}$ 
A

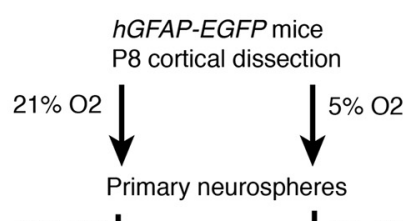

$21 \% \mathrm{O} 2\rfloor \downarrow^{5 \% \mathrm{O} 2}$

Secondary neurospheres $\longrightarrow$

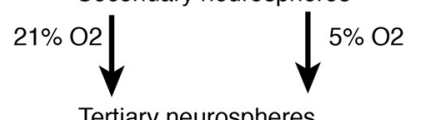

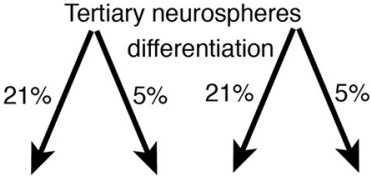

phenotypic characterization
B
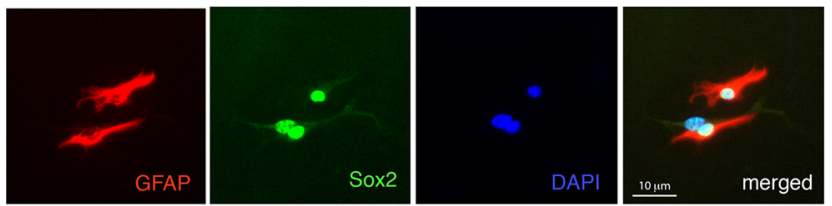

dissociation

3 days $\downarrow 21 \%$ or $5 \%$ O2

cell proliferation

cell survival
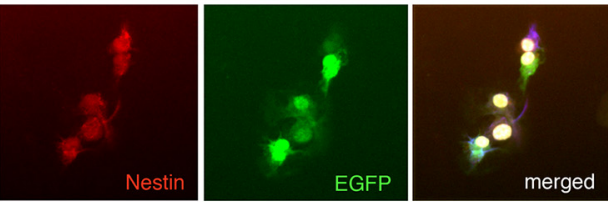
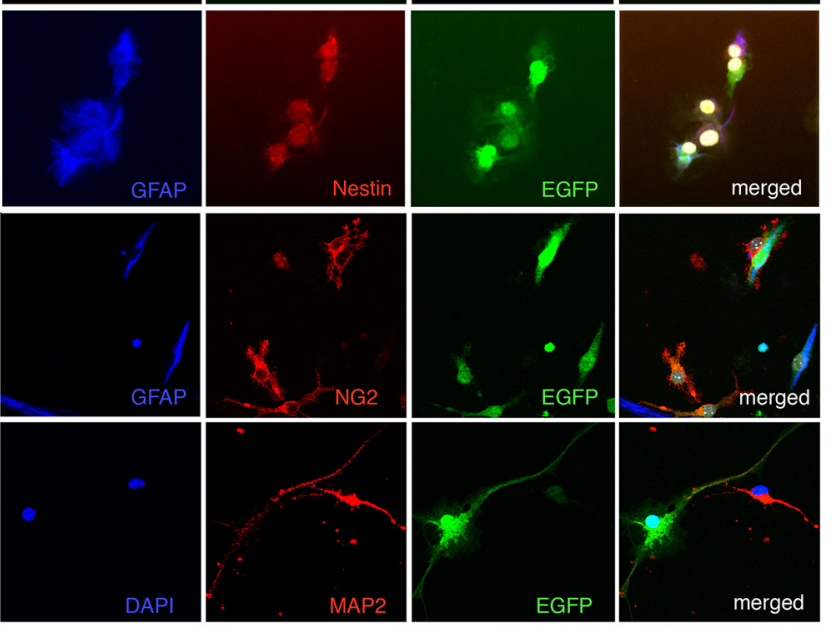

D

Caspase 3

$\mathrm{Nx}=2.9 \%$ of DAPI+ cells

$\mathrm{H} x=0.8 \%$ of DAPI+ cells

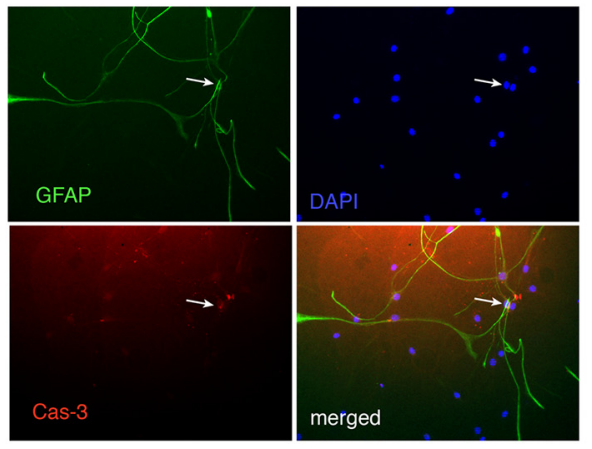

G

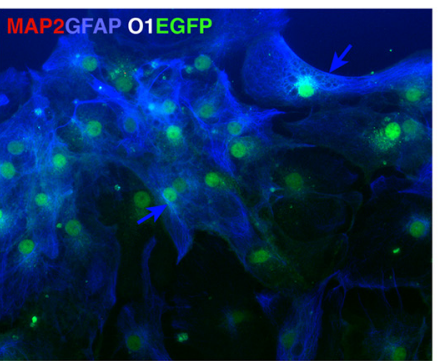

$\%$ total EGFP+ neurospheres
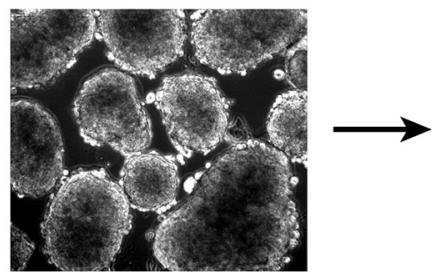

$5 \% \mathrm{O} 2$
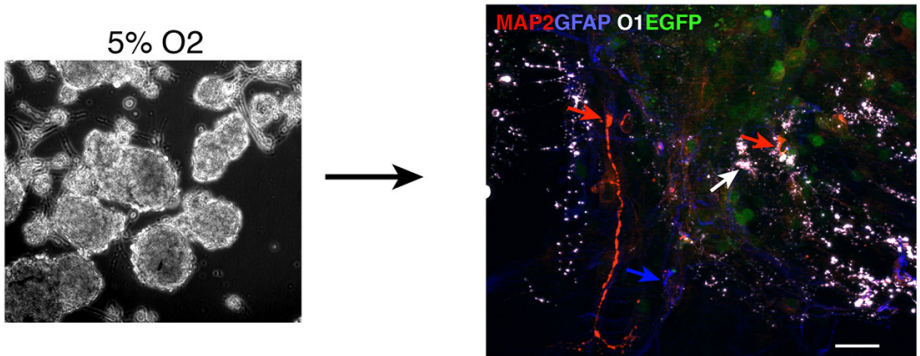

$21 \% 02$

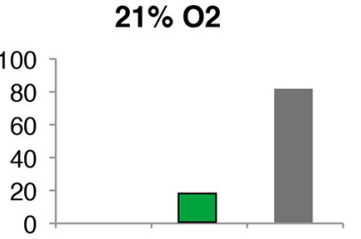

$5 \% 02$

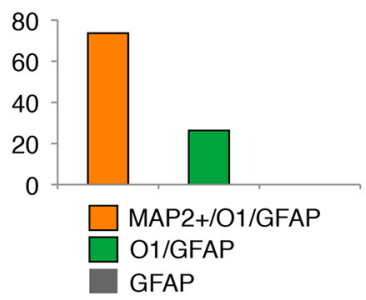

Figure 9. Exposure to low $\mathrm{O}_{2}$ in vitro maintains pluripotent fate potential in cortical $\mathrm{GFAP}^{+}$cells. $\boldsymbol{A}$, Scheme of the experimental paradigm. $\boldsymbol{B}$, EGFP $^{+}$cells dissociated from secondary neurospheres exhibit astroglial phenotype and were directly apposed to Sox2-, NG2-, or MAP2-immunoreactive cells that were weakly EGFP ${ }^{+}$, suggesting a progenitor-progeny relationship. $C$, Primary neurospheres obtained under $5 \% \mathrm{O}_{2}$ exhibit smaller size. $\boldsymbol{D}$, Culture in $21 \% \mathrm{O}_{2}$ for 3 delicited a small increase in apoptotic cells as detected by caspase-3 immunostaining (D, arrow) compared with culturing in $5 \% \mathrm{O}_{2}$. Hx, Hypoxic; $\mathrm{Nx}$, normoxic. $\boldsymbol{E}, \boldsymbol{F}$, Tertiary neurospheres continuously grown in either 21 or $5 \% \mathrm{O}_{2}$ were plated onto an adhesive substrate (Figure legend continues.) 
stem cells still exhibited weak EGFP, which can remain in cells of astroglial origin after they have downregulated GFAP expression.

Active caspase- 3 was detected in 2.9 and $0.8 \%$ of cells kept for $3 \mathrm{~d}$ in 21 and $5 \% \mathrm{O}_{2}$, respectively $\left(n=241\right.$ and $263 \mathrm{DAPI}^{+}$ cells scored in the two conditions), suggesting that low oxygen may promote cell survival in a small subset of cells (Fig. 9D). This was confirmed by an independent experiment using TUNEL staining, which revealed that $2 \pm 0.6 \%$ of the DAPI ${ }^{+}$ cells were TUNEL $^{+}$after $3 \mathrm{~d}$ in $5 \% \mathrm{O}_{2}$ as opposed to $13.7 \pm$ $2.4 \%$ in $21 \% \mathrm{O}_{2}$.

We observed a consistent decrease in neurosphere size but no consistent change in neurosphere number at $5 \% \mathrm{O}_{2}$ compared with $21 \% \mathrm{O}_{2}$ (Fig. 9C,E and data not shown). To investigate the effect of in vitro hypoxia on the potential of neurosphere-forming cells, we cultured single neurospheres under differentiating conditions by withdrawing growth factors and allowing them to adhere to a substrate. After $15 \mathrm{~d}$, neurosphere cultures were subjected to triple immunostaining for neurons (MAP2), astrocytes (GFAP), and oligodendrocytes (O1). We found that $75 \%$ of the neurospheres that were generated under $5 \% \mathrm{O}_{2}$ produced neurons, astrocytes, and oligodendrocytes, and $\sim 25 \%$ produced astrocytes and oligodendrocytes but no neurons, suggesting that most of the neurosphere-forming NSC exhibited pluripotency (Fig. $9 F, G$ ). In contrast, neurospheres generated in $21 \% \mathrm{O}_{2}$ generated glial lineages and no neurons; $80 \%$ of the neurospheres generated in $21 \% \mathrm{O}_{2}$ produced only astrocytes, and $20 \%$ produced astrocytes and oligodendrocytes during differentiation (Fig. $9 F, G$ ). The results of a repeat experiment performed with a different set of mice were not significantly different from the first experiment by factorial ANOVA: $70 \%$ of neurospheres generated in $5 \% \mathrm{O}_{2}$ generated all three lineages and, conversely, $86 \%$ of neurospheres generated in $21 \% \mathrm{O}_{2}$ produced only glia. In both experiments, exposure to low or high $\mathrm{O}_{2}$ during the differentiation stage did not substantially alter the fate potential of neurospheres, suggesting that differential $\mathrm{O}_{2}$ levels affect the fate potential when cells are still at the undifferentiated (NSC) stage. Combined with the results obtained from in vivo hypoxic mice, these data suggest that exposure to low $\mathrm{O}_{2}$ induces or maintains pluripotency in a GFAP ${ }^{+}$cell population residing outside of the classic neurogenic areas, such as the cerebral cortex.

\section{Discussion}

We examined the fate of $\mathrm{GFAP}^{+}$cells after an early postnatal hypoxic insult by in vivo genetic fate mapping using the GCE mouse line. By inducing systemic and local recombination of a reporter gene in $\mathrm{GFAP}^{+}$cells in juvenile mice (P12-P15), we demonstrate that $\mathrm{GFAP}^{+}$cells in the cerebral cortex generate neurons. GFAP ${ }^{+}$cells also generate cortical and white matter oligodendrocytes in the juvenile period, and both neurogenesis and oligodendrogenesis from this lineage is enhanced during recovery from perinatal hypoxia.

Both cortical astrocytes and astrocyte-like $\mathrm{GFAP}^{+}$stem cells in the classical neurogenic regions originate from radial glia, pluripotent cells that exhibit an astroglial phenotype and express the hGFAP promoter (Voigt, 1989; Merkle et al., 2004). GFAP ${ }^{+}$cells in the SVZ remain pluripotent throughout the lifespan, whereas

$\leftarrow$

(Figure legend continued.) and grown under differentiating conditions. Triple MAP2/01/ GFAP immunostaining revealed that $>75 \%$ of the neurospheres cultured in $5 \% 0_{2}$ were able to generate neurons, astrocytes, and oligodendrocytes, whereas none of the neurospheres cultured in $21 \% \mathrm{O}_{2}$ were neurogenic, and $80 \%$ could give rise to astrocytes only. parenchymal $\mathrm{GFAP}^{+}$cells typically produce only astrocytes in the postnatal brain (Laywell et al., 2000; Berninger, 2010). Furthermore, the cortex under standard conditions appears to be unable to sustain the development and integration of new neurons during postnatal development. However, we show that $\mathrm{GFAP}^{+}$glia, marked via irreversible induction of a reporter gene at P12-P15, can generate neurons that survive until adulthood. Furthermore, cortical GFAP ${ }^{+}$cells marked via intracortical tamoxifen administration at P20 can locally generate cortical neurons in hypoxia-reared mice. Previous studies have failed to reveal neurogenesis from astroglial cells in the adult neocortex in vivo (Buffo et al., 2008). Interestingly, $\mathrm{GFAP}^{+}$cells isolated from the cortex of hypoxic-reared mice give rise to pluripotent neurospheres in vitro, indicating a long-term change in their intrinsic potential.

A recent study suggests that $\mathrm{Tbr}{ }^{+}$cells, which arise in the dorsal SVZ from Neurogenin $2^{+}$precursors, may migrate from the SVZ to the cortex after targeted callosal projection neuron degeneration (Brill et al., 2009). Consistent with this, we found that $\mathrm{Tbr}^{+}$proliferating precursors arise from fate-mapped $\mathrm{GFAP}^{+} \mathrm{SVZ}$ cells in juvenile mice, but these cells do not migrate to the $\mathrm{OB}$, at least at the time point examined. It is possible that $\mathrm{Tbr}^{+}$cells populating the SVZ might migrate to the cortex. Although we have not directly investigated the fate of $\mathrm{Tbr} 2{ }^{+}$cells arising from the SVZ, we observed that these progenitors were persistently increased in both the SVZ and subcortical white matter of hypoxic-reared mice, suggesting another possible source of neuronal progenitors.

Control experiments excluded the occurrence of ectopic recombination in neurons or in oligodendrocytes and their progenitors, confirming the specificity of lineage tracing driven by our GCE transgenic mouse line to GFAP ${ }^{+}$cells. At both 1 and $3 \mathrm{~d}$ after the first tamoxifen injection, $100 \%$ of cortical reporter targeting was restricted to $S 100 \beta^{+}$and/or GFAP ${ }^{+}$cells, and, $1 \mathrm{~d}$ after recombination, virtually none expressed NG2. Furthermore, all cells expressing the Cre protein were $\mathrm{GFAP}^{+}$and NG2 negative. Thus, the small fraction of reporter ${ }^{+}$cells that expressed NG2 and PDGFR $\alpha 3 \mathrm{~d}$ after recombination (P15) are likely generated from $\mathrm{GFAP}^{+}$cells. Finally, neither targeting efficiency nor specificity was affected by previous hypoxic rearing of the mice.

The mouse model of chronic sublethal hypoxia that we use reproduces the partial recovery in cortical volume, neuron number, and cognitive functions observed in the preterm human subjects (Vaccarino and Ment, 2004; Mayoral et al., 2009; Scafidi et al., 2009). In contrast to widely studied injury models in adults, such as ischemic stroke and stab wound, our model of global hypoxia in juveniles does not lead to reactive glial changes, such as increased proliferation and hypertrophy. When we examined the astroglia-derived cortical neurons several weeks after induction, these cells appeared to be integrated in the network as indicated by their normal morphology, dendritic and axonal extension, and synaptic connections. This, again, is in contrast to previous studies examining various injury models in which $\mathrm{Dcx}^{+}$ neuroblasts or $\mathrm{NeuN}^{+}$neurons were found surrounding the lesion but did not survive long enough to reach a mature, functional, and integrated state (Arvidsson et al., 2002; Parent et al., 2002; Komitova et al., 2005; Ramaswamy et al., 2005; SundholmPeters et al., 2005; Yang et al., 2007; Zhang et al., 2008). Such plasticity possibly explains the surprising cognitive recovery often found in preterm children.

In addition to neurons, juvenile astroglial cells generate oligodendrocyte lineage cells in various regions. At P15, $\sim 10 \%$ of 
reporter ${ }^{+}$cells expressed OPC markers (NG2/PDGFR $\alpha$ ) in the cortex and white matter but not markers of mature oligodendrocytes. At P35, reporter ${ }^{+} / \mathrm{NG}^{+}$cells were still present in the cortex, but now $\sim 6 \%$ of reporter ${ }^{+}$cells acquired an oligodendrocyte fate (Fig. 3D). Furthermore, hypoxia increased the number and proportion of cortical NG2 ${ }^{+}$and Rip ${ }^{+}$cells generated from the $\mathrm{GFAP}^{+}$lineage (Figs. $3 L, 4 E$ ). These data raise the question of whether the newly generated neurons we have observed in the cerebral cortex are generated from oligodendrocyte precursors. Indeed, previous research has shown that cells expressing NG2 or PDGFR $\alpha$ have the ability to generate telencephalic neurons. The majority of the oligodendrocyte-derived neurons appears to be excitatory and is present in both dorsal and ventral neocortex (Rivers et al., 2008; Guo et al., 2009). Although results from our Cre costaining would suggest it is unlikely that we have an initial mistargeting of oligodendrocytes, it is, however, possible that the initial astroglial progenitors generate $\mathrm{NG} 2^{+} / \mathrm{PDGFR} \alpha{ }^{+}$OPCs that, in turn, give rise to the observed neurons. However, this appears to be unlikely, because no neurons are generated from NG2 ${ }^{+} / \mathrm{PDGFR} \alpha^{+}$oligodendrocyte lineage cells constitutively targeted during embryogenesis or in the postnatal period (Zhu et al., 2008; Kang et al., 2010). This is further supported by our in vitro experiments showing that pluripotent neurospheres can be obtained from cortical EGFP ${ }^{+}$cells that have characteristics of immature astroglia and not OPCs (discussed below). Thus, the available data strongly suggest that $\mathrm{GFAP}^{+}$cells represent a common, pluripotent ancestor for both neurons and oligodendrocytes in the early postnatal period.

Flow cytometry experiments revealed that $>80 \%$ of cortical $\mathrm{EGFP}^{+}$cells, reporter-tagged in vivo and sorted out from the cortex of hypoxic-reared GCE mice at P15, expressed GFAP but not NG2 proteins, although a very small population $(3.5 \%,<50$ cells) coexpressed GFAP and NG2. The cortical EGFP ${ }^{+}$cells isolated from hypoxic mice could generate self-renewing neurospheres that, eventually, gave rise to both neurons and OPCs in vitro; in contrast, cortical $\mathrm{EGFP}^{+}$cells isolated from $\mathrm{P} 15$ normoxic mice could not generate neurospheres. Although it is possible that these neurospheres arose from the small fraction of $\mathrm{GFAP}^{+} / \mathrm{NG}^{+}$cells, we think this is unlikely because of its small size and because, at least in adult mice, astroglia but not NG2 cells can generate pluripotent neurospheres (Buffo et al., 2008; Zhu et al., 2008). A similar ability to form pluripotent neurospheres was induced in $h G F A P$ promoter ${ }^{+}$cortical glial cells obtained from slightly younger mice (P8) by several days of culture in low oxygen conditions. The low oxygen treatment did not change the phenotypic properties of the $h$ GFAP promoter ${ }^{+}$cortical cells (i.e., Sox2 or GFAP expression), but it affected their fate because most neurospheres cultured in low $\mathrm{O}_{2}$ were pluripotent, whereas those kept under standard $21 \% \mathrm{O}_{2}$ were generating mostly glia. Indeed, previous reports demonstrated a progressive fate restriction of astroglial cells in the postnatal cortical parenchyma (Laywell et al., 2000; Berninger, 2010; Heinrich et al., 2010). As expected, reporter ${ }^{+}$cells isolated from the SVZ remained pluripotent in both normoxic and hypoxic conditions. Generation of other lineages from the astroglial precursors appeared to occur after cell division, because low-density cultures of cells dissociated from neurospheres of $h$ GFAP-GFP mice cultured in low $\mathrm{O}_{2}$ contained many cell doublets in which astroglial cells strongly $\mathrm{EGFP}^{+}$were directly apposed to weakly stained $\mathrm{EGFP}^{+}$cells expressing NG2 or MAP2, suggesting a precursor-progeny relationship. Together, the above results suggest that low $\mathrm{O}_{2}$ can induce long-term changes in the potential of such astroglial-type cells, at least in young mammals.
The low $\mathrm{O}_{2}$ paradigm in vitro is certainly very different from the in vivo hypoxia, because the NSCs exposed to hypoxia in vivo are also exposed to many secondary direct and indirect cellular interactions attributable to the complex microenvironment of their local niches. However, we did the in vitro hypoxia experiment to assess whether variations in oxygen level could directly influence astroglial cells/NSCs, independently of their environment. We also know that, when cells maintained in vitro under certain oxygen conditions are subsequently exposed to relative decreases in oxygen conditions, these cells exhibit a hypoxic response, characterized by increased HIF $1 \alpha$ expression, when the oxygen is lowered in vitro.

Concerning the mechanism of the apparent fate change in these cortical GFAP ${ }^{+}$cells, hypoxia could maintain such cells into a more immature "radial glia"-like state, or it could induce the selective proliferation or survival of a subset of these cells exhibiting neurogenic properties. That is, hypoxia could either "select" among distinct cellular entities sharing GFAP expression but with different developmental potential, or maintain pluripotency in the whole population of GFAP ${ }^{+}$cells, which are rapidly undergoing fate restriction in this developmental time period and may be oscillating among functionally diverse states. No change in rate of cell division could be evidenced when cortical astroglial-type cells were exposed to low oxygen in vitro, which argues against a strong selective effect of in vitro hypoxic conditions. Exposure of immature cortical astroglial cells in vitro to low $\mathrm{O}_{2}$ promoted cell survival, but the rates of cell death were overall fairly low and probably not sufficient to explain the relatively large effects of hypoxia on cell fate. Altogether, our data show that chronic hypoxia in young mice promotes pluripotency in $\mathrm{GFAP}^{+}$cells, which likely involves complex effects at the genomic level, maintaining astroglial cells that have NSC properties. Hypoxia appears to have an impact on their intrinsic cellular potential, as revealed by the fact that fate-mapped $\mathrm{GFAP}^{+}$cells derived from hypoxic pups ex vivo could form pluripotent neurospheres in vitro. However, prolonged self-renewal and neurogenesis of $\mathrm{GFAP}^{+}$cells may be limited by endogenous factors in the cortical parenchyma in vivo.

\section{References}

Arvidsson A, Collin T, Kirik D, Kokaia Z, Lindvall O (2002) Neuronal replacement from endogenous precursors in the adult brain after stroke. Nat Med 8:963-970.

Berninger B (2010) Making neurons from mature glia: a far-fetched dream? Neuropharmacology 58:894-902.

Brenner M, Kisseberth WC, Su Y, Besnard F, Messing A (1994) GFAP promoter directs astrocyte-specific expression in transgenic mice. J Neurosci 14:1030-1037.

Brill MS, Ninkovic J, Winpenny E, Hodge RD, Ozen I, Yang R, Lepier A, Gascón S, Erdelyi F, Szabo G, Parras C, Guillemot F, Frotscher M, Berninger B, Hevner RF, Raineteau O, Götz M (2009) Adult generation of glutamatergic olfactory bulb interneurons. Nat Neurosci 12:1524-1533.

Buffo A, Rite I, Tripathi P, Lepier A, Colak D, Horn AP, Mori T, Götz M (2008) Origin and progeny of reactive gliosis: a source of multipotent cells in the injured brain. Proc Natl Acad Sci U S A 105:3581-3586.

Chahboune H, Ment LR, Stewart WB, Rothman DL, Vaccarino FM, Hyder F, Schwartz ML (2009) Hypoxic injury during neonatal development in murine brain: correlation between in vivo DTI findings and behavioral assessment. Cereb Cortex 19:2891-2901.

Doetsch F, Caillé I, Lim DA, García-Verdugo JM, Alvarez-Buylla A (1999) Subventricular zone astrocytes are neural stem cells in the adult mammalian brain. Cell 97:703-716.

Englund C, Fink A, Lau C, Pham D, Daza RA, Bulfone A, Kowalczyk T, Hevner RF (2005) Pax6, Tbr2, and Tbr1 are expressed sequentially by radial glia, intermediate progenitor cells, and postmitotic neurons in developing neocortex. J Neurosci 25:247-251. 
Faedo A, Ficara F, Ghiani M, Aiuti A, Rubenstein JL, Bulfone A (2002) Developmental expression of the T-box transcription factor T-bet/Tbx21 during mouse embryogenesis. Mech Dev 116:157-160.

Fagel DM, Ganat Y, Silbereis J, Ebbitt T, Stewart W, Zhang H, Ment LR, Vaccarino FM (2006) Cortical neurogenesis enhanced by chronic perinatal hypoxia. Exp Neurol 199:77-91.

Fagel DM, Ganat Y, Cheng E, Silbereis J, Ohkubo Y, Ment LR, Vaccarino FM (2009) Fgfrl is required for cortical regeneration and repair after perinatal hypoxia. J Neurosci 29:1202-1211.

Felling RJ, Snyder MJ, Romanko MJ, Rothstein RP, Ziegler AN, Yang Z, Givogri MI, Bongarzone ER, Levison SW (2006) Neural stem/progenitor cells participate in the regenerative response to perinatal hypoxia/ ischemia. J Neurosci 26:4359-4369.

Filippov V, Kronenberg G, Pivneva T, Reuter K, Steiner B, Wang LP, Yamaguchi M, Kettenmann H, Kempermann G (2003) Subpopulation of nestin-expressing progenitor cells in the adult murine hippocampus shows electrophysiological and morphological characteristics of astrocytes. Mol Cell Neurosci 23:373-382.

Ganat YM, Silbereis J, Cave C, Ngu H, Anderson GM, Ohkubo Y, Ment LR, Vaccarino FM (2006) Early postnatal astroglial cells produce multilineage precursors and neural stem cells in vivo. J Neurosci 26:8609-8621.

Garcia AD, Doan NB, Imura T, Bush TG, Sofroniew MV (2004) GFAPexpressing progenitors are the principal source of constitutive neurogenesis in adult mouse forebrain. Nat Neurosci 7:1233-1241.

Gundersen HJ, Bagger P, Bendtsen TF, Evans SM, Korbo L, Marcussen N, Møller A, Nielsen K, Nyengaard JR, Pakkenberg B, Sørensen FB, Vesterby A, West MJ (1988) The new stereological tools: disector, fractionator, nucleator, and point sampled intercepts and their use in pathological research and diagnosis. APMIS 96:857-881.

Guo F, Ma J, McCauley E, Bannerman P, Pleasure D (2009) Early postnatal proteolipid promoter-expressing progenitors produce multilineage cells in vivo. J Neurosci 29:7256-7270.

Hachem S, Aguirre A, Vives V, Marks A, Gallo V, Legraverend C (2005) Spatial and temporal expression of S100B in cells of oligodendrocyte lineage. Glia 51:81-97.

Heinrich C, Blum R, Gascón S, Masserdotti G, Tripathi P, Sánchez R, Tiedt S, Schroeder T, Götz M, Berninger B (2010) Directing astroglia from the cerebral cortex into subtype specific functional neurons. PLoS Biol 8:e1000373.

Howard SB, Etgen AM, Barfield RJ (1984) Antagonism of central estrogen action by intracerebral implants of tamoxifen. Horm Behav 18:256-266.

Kang SH, Fukaya M, Yang JK, Rothstein JD, Bergles DE (2010) NG2+ CNS glial progenitors remain committed to the oligodendrocyte lineage in postnatal life and following neurodegeneration. Neuron 68:668-681.

Kesler SR, Reiss AL, Vohr B, Watson C, Schneider KC, Katz KH, MallerKesselman J, Silbereis J, Constable RT, Makuch RW, Ment LR (2008) Brain volume reductions within multiple cognitive systems in male preterm children at age twelve. J Pediatr 152:513-520, 520.e1.

Komitova M, Zhao LR, Gidö G, Johansson BB, Eriksson P (2005) Postischemic exercise attenuates whereas enriched environment has certain enhancing effects on lesion-induced subventricular zone activation in the adult rat. Eur J Neurosci 21:2397-2405.

Laywell ED, Rakic P, Kukekov VG, Holland EC, Steindler DA (2000) Identification of a multipotent astrocytic stem cell in the immature and adult mouse brain. Proc Natl Acad Sci U S A 97:13883-13888.

Lim DA, Tramontin AD, Trevejo JM, Herrera DG, García-Verdugo JM, Alvarez-Buylla A (2000) Noggin antagonizes BMP signaling to create a niche for adult neurogenesis. Neuron 28:713-726.

Luskin MB (1993) Restricted proliferation and migration of postnatally generated neurons derived from the forebrain ventricular zone. Neuron 11:173-189.

Luu TM, Ment LR, Schneider KC, Katz KH, Allan WC, Vohr BR (2009) Lasting effects of preterm birth and neonatal brain hemorrhage at 12 years of age. Pediatrics 123:1037-1044.

Matthias K, Kirchhoff F, Seifert G, Hüttmann K, Matyash M, Kettenmann H, Steinhäuser C (2003) Segregated expression of AMPA-type glutamate receptors and glutamate transporters defines distinct astrocyte populations in the mouse hippocampus. J Neurosci 23:1750-1758.

Mayoral SR, Omar G, Penn AA (2009) Sex differences in a hypoxia model of preterm brain damage. Pediatr Res 66:248-253.
Menn B, Garcia-Verdugo JM, Yaschine C, Gonzalez-Perez O, Rowitch D, Alvarez-Buylla A (2006) Origin of oligodendrocytes in the subventricular zone of the adult brain. J Neurosci 26:7907-7918.

Ment LR, Constable RT (2007) Injury and recovery in the developing brain: evidence from functional MRI studies of prematurely born children. Nat Clin Pract Neurol 3:558-571.

Merkle FT, Tramontin AD, García-Verdugo JM, Alvarez-Buylla A (2004) Radial glia give rise to adult neural stem cells in the subventricular zone. Proc Natl Acad Sci U S A 101:17528-17532.

Mohyeldin A, Garzón-Muvdi T, Quiñones-Hinojosa A (2010) Oxygen in stem cell biology: a critical component of the stem cell niche. Cell Stem Cell 7:150-161.

Mori T, Tanaka K, Buffo A, Wurst W, Kühn R, Götz M (2006) Inducible gene deletion in astroglia and radial glia-a valuable tool for functional and lineage analysis. Glia 54:21-34.

Nakagomi T, Taguchi A, Fujimori Y, Saino O, Nakano-Doi A, Kubo S, Gotoh A, Soma T, Yoshikawa H, Nishizaki T, Nakagomi N, Stern DM, Matsuyama T (2009) Isolation and characterization of neural stem/ progenitor cells from post-stroke cerebral cortex in mice. Eur J Neurosci 29:1842-1852.

Nakamura T, Colbert MC, Robbins J (2006) Neural crest cells retain multipotential characteristics in the developing valves and label the cardiac conduction system. Circ Res 98:1547-1554.

Nishiyama A, Lin XH, Giese N, Heldin CH, Stallcup WB (1996) Colocalization of NG2 proteoglycan and PDGF alpha-receptor on O2A progenitor cells in the developing rat brain. J Neurosci Res 43:299-314.

Palmer TD, Willhoite AR, Gage FH (2000) Vascular niche for adult hippocampal neurogenesis. J Comp Neurol 425:479-494.

Panchision DM (2009) The role of oxygen in regulating neural stem cells in development and disease. J Cell Physiol 220:562-568.

Parent JM, Vexler ZS, Gong C, Derugin N, Ferriero DM (2002) Rat forebrain neurogenesis and striatal neuron replacement after focal stroke. Ann Neurol 52:802-813.

Pistollato F, Chen HL, Schwartz PH, Basso G, Panchision DM (2007) Oxygen tension controls the expansion of human CNS precursors and the generation of astrocytes and oligodendrocytes. Mol Cell Neurosci 35:424-435.

Ramaswamy S, Goings GE, Soderstrom KE, Szele FG, Kozlowski DA (2005) Cellular proliferation and migration following a controlled cortical impact in the mouse. Brain Res 1053:38-53.

Rietze RL, Reynolds BA (2006) Neural stem cell isolation and characterization. Methods Enzymol 419:3-23.

Rivers LE, Young KM, Rizzi M, Jamen F, Psachoulia K, Wade A, Kessaris N, Richardson WD (2008) PDGFRA/NG2 glia generate myelinating oligodendrocytes and piriform projection neurons in adult mice. Nat Neurosci 11:1392-1401.

Santilli G, Lamorte G, Carlessi L, Ferrari D, Rota Nodari L, Binda E, Delia D, Vescovi AL, De Filippis L (2010) Mild hypoxia enhances proliferation and multipotency of human neural stem cells. PLoS One 5:e8575.

Scafidi J, Fagel DM, Ment LR, Vaccarino FM (2009) Modeling premature brain injury and recovery. Int J Dev Neurosci 27:863-871.

Schmitz C, Hof PR (2005) Design-based stereology in neuroscience. Neuroscience 130:813-831.

Seri B, García-Verdugo JM, McEwen BS, Alvarez-Buylla A (2001) Astrocytes give rise to new neurons in the adult mammalian hippocampus. J Neurosci 21:7153-7160.

Silbereis J, Cheng E, Ganat YM, Ment LR, Vaccarino FM (2009) Precursors with glial fibrillary acidic protein promoter activity transiently generate GABA interneurons in the postnatal cerebellum. Stem Cells 27:11521163.

Silbereis J, Heintz T, Taylor MM, Ganat Y, Ment LR, Bordey A, Vaccarino F (2010) Astroglial cells in the external granular layer are precursors of cerebellar granule neurons in neonates. Mol Cell Neurosci 44:362-373.

Soriano P (1999) Generalized lacZ expression with the ROSA26 Cre reporter strain. Nat Genet 21:70-71.

Sundholm-Peters NL, Yang HK, Goings GE, Walker AS, Szele FG (2005) Subventricular zone neuroblasts emigrate toward cortical lesions. J Neuropathol Exp Neurol 64:1089-1100.

Turner CP, Seli M, Ment L, Stewart W, Yan H, Johansson B, Fredholm BB, Blackburn M, Rivkees SA (2003) Al adenosine receptors mediate hypoxiainduced ventriculomegaly. Proc Natl Acad Sci U S A 100:11718-11722.

Vaccarino FM, Ment LR (2004) Injury and repair in developing brain. Arch Dis Child Fetal Neonatal Ed 89:F190-F192. 
Voigt T (1989) Development of glial cells in the cerebral wall of ferrets: direct tracing of their transformation from radial glia into astrocytes. J Comp Neurol 289:74-88.

Volpe JJ (1991) Cognitive deficits in premature infants. N Engl J Med 325:276-278.

Volpe JJ (1998) Neurologic outcome of prematurity. Arch Neurol 55:297-300.

Walton NM, Sutter BM, Chen HX, Chang LJ, Roper SN, Scheffler B, Steindler DA (2006) Derivation and large-scale expansion of multipotent astroglial neural progenitors from adult human brain. Development 133:3671-3681.

Weiss J, Takizawa B, McGee A, Stewart WB, Zhang H, Ment L, Schwartz M, Strittmatter S (2004) Neonatal hypoxia suppresses oligodendrocyte Nogo-A and increases axonal sprouting in a rodent model for human prematurity. Exp Neurol 189:141-149.
West MJ (1993) New stereological methods for counting neurons. Neurobiol Aging 14:275-285.

Wood RI, Williams SJ (2001) Steroidal control of male hamster sexual behavior in Me and MPOA: effects of androgen dose and tamoxifen. Physiol Behav 72:727-733.

Yang Z, Covey MV, Bitel CL, Ni L, Jonakait GM, Levison SW (2007) Sustained neocortical neurogenesis after neonatal hypoxic/ischemic injury. Ann Neurol 61:199-208.

Zhang L, Goldman JE (1996) Developmental fates and migratory pathways of dividing progenitors in the postnatal rat cerebellum. J Comp Neurol 370:536-550.

Zhang RL, Zhang ZG, Chopp M (2008) Ischemic stroke and neurogenesis in the subventricular zone. Neuropharmacology 55:345-352.

Zhu X, Bergles DE, Nishiyama A (2008) NG2 cells generate both oligodendrocytes and gray matter astrocytes. Development 135:145-157. 